\title{
DÜBLIN
}

Technological University Dublin

ARROW@TU Dublin

\section{Phenology of Cupressaceae urban infrastructure related to its pollen content and meteorological variables}

\author{
A. Monroy-Colín \\ Universidad de Extremadura \\ J. M. Maya-Manzano \\ Technological University Dublin, jose.manzano@tudublin.ie \\ I. Silva-Palacios \\ Universidad de Extremadura
}

See next page for additional authors

Follow this and additional works at: https://arrow.tudublin.ie/scschcpsart

Part of the Allergy and Immunology Commons, Botany Commons, Meteorology Commons, and the Plant Biology Commons

\section{Recommended Citation}

Monroy-Colín, A., Maya-Manzano, J.M., Silva-Palacios, I. et al. Phenology of Cupressaceae urban infrastructure related to its pollen content and meteorological variables. Aerobiologia 36, 459-479

(2020). DOI: 10.1007/s10453-020-09645-9

This Article is brought to you for free and open access by the School of Chemical and Pharmaceutical Sciences at ARROW@TU Dublin. It has been accepted for inclusion in Articles by an authorized administrator of ARROW@TU Dublin. For more information, please contact arrow.admin@tudublin.ie, aisling.coyne@tudublin.ie, gerard.connolly@tudublin.ie.

Funder: Regional Government, Junta de Extremadura (Spain); National Commission of Science and Technology of Mexico (CONACyT); Irish Environmental Protection Agency

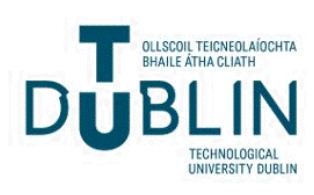




\section{Authors}

A. Monroy-Colín, J. M. Maya-Manzano, I. Silva-Palacios, R. Tormo-Molina, R. Pecero-Casimiro, Á. GonzaloGarijo, and S. Fernández-Rodríguez 


\title{
Phenology of Cupressaceae urban infrastructure related to its pollen content and meteorological variables
}

\author{
A. Monroy-Colín · J. M. Maya-Manzano - I. Silva-Palacios · R. Tormo-Molina • \\ R. Pecero-Casimiro • Á. Gonzalo-Garijo · S. Fernández-Rodríguez
}

Received: 13 December 2019/Accepted: 19 May 2020/Published online: 29 May 2020

(C) Springer Nature B.V. 2020

\begin{abstract}
Cupressaceae pollen is one of the major airborne allergens of the Mediterranean region and in other regions around the world. Pollen production of these species causes considerable allergic problems during winter, being this type of pollen the most abundant in this period of the year. This work aims to relate phenology, meteorology and airborne pollen records in these species. Aerobiological sampling was carried out in Badajoz (SW Spain) from 2016 to 2018 using Hirst-type volumetric sampler. Pollination phenology was studied in 50 specimens, ten of Cupressus macrocarpa, ten of Cupressus arizonica, 15 of Cupressus sempervirens and 15 of Platycladus orientalis with a frequency of 3-4 days on average during the months of January to March. In all cases, five specimens were in the surrounding of pollen station
\end{abstract}

A. Monroy-Colín · R. Tormo-Molina · R. PeceroCasimiro

Department of Plant Biology, Ecology and Earth Sciences, Faculty of Science, University of Extremadura, Avda. Elvas s/n, Badajoz, Spain

J. M. Maya-Manzano

School of Chemical and Pharmaceutical Sciences, Technological University Dublin, Kevin Street, Dublin, Ireland

J. M. Maya-Manzano

Center of Allergy and Environment (ZAUM), Technische Universität München/Helmholtz Center, Biedersteiner Str 29, Munich, Germany and at least five of them $4 \mathrm{~km}$ apart. For phenology, $\mathrm{BBCH}$ methodology was used. Daily data for the whole period and hourly data for the last 2 years were analyzed, including pollen records and meteorology. Comparison between pollen records and sources distribution was assessed. Main pollen season lasted on average 91 (89-94) days. In all the years, the peaks of phenology of the different species can be matched with peaks of airborne pollen records, considering that rain can prevent a more precise correspondence.

Keywords Phenology $\cdot$ Botany $\cdot$ Cupressaceae pollen · Urban maps · Meteorology · Allergy

\footnotetext{
I. Silva-Palacios

Department of Applied Physics, Engineering Agricultural School, University of Extremadura, Avda. Adolfo Suárez s/n, Badajoz, Spain

Á. Gonzalo-Garijo

Department of Allergology, Badajoz University Hospital, Avda. Elvas s/n, Badajoz, Spain

S. Fernández-Rodríguez ( $\square)$

Department of Construction, School of Technology,

University of Extremadura, Avda. de la Universidad s/n,

Cáceres, Spain

e-mail: santiferro@unex.es
} 


\section{Introduction}

Cupressaceae family is integrated by 30 genera with 133 species of evergreen shrubs and trees, distributed worldwide (Schulzz et al. 2005), being the most representative genera in Europe: Cupressus (cypresses), Juniperus (junipers), Chamaecyparis (white cedar of Oregon), Calocedrus (white cedar of California) and Platycladus (Chinese thuja) (Page 1990; Schulzz et al. 2005). The two former taxa are endemic species in Europe, and the rest are planted as ornamentals. Many members of the cypress family are important as timber sources or ornamentals, especially arborvitae, cypress, bald cypress and juniper (Chhaya and Johri 1997). They also contain useful oils, resins and tannins (Chhaya and Johri 1997 and James 2015). They are widely used for windbreak hedges on account of their fast growth, low water needs and low cost (Charpin et al. 2017). In this area, pollen from early pollinating species (e.g., Juniperus oxycedrus) is produced in October and November, while pollination by late pollinating species (e.g., Cupressus sempervirens) can occur up to late April or May (Charpin et al. 2017). C. sempervirens is the most common pollinating species, and it accounts for half of the total of atmospheric pollen concentration over season (Charpin et al. 2017).

The leaves of these plants are scale-like opposite or needle-like (Watson and Eckenwalder 1993). Nevertheless, the last classification (Christenhusz et al. 2011) using molecular phylogenetic techniques includes the genus from the old Taxodiaceae family as Taxodium, Cryptomeria, Sequoiadendron and Sequoia with species used as ornamentals with minor representation. The male reproductive structures are borne at the ends of short twigs. The female cones are terminal, with opposite or whorled scales, consisting of both a fused bract and a scale. The seeds cones, usually woody (fleshy in Juniperus), have erect ovules (James 2015).

The pollen grains have spheroidal morphology, with a variable size between 19 and $38 \mu \mathrm{m}$, unapertured and with a thin exine with fine and thick granules irregularly scattered (orbicles) (Bortenschlager 1989). Occasionally, pollen grains can break off leaving the protoplast wrapped in a very thick and gelatinous intine (Chhaya and Johri 1997; Schulzz et al. 2005; James 2015). Pollen grains morphology do not provide characteristics to differentiate the genera of this family (stenopalynous character), being in aerobiological studies all species included in the same pollen type. Consequently, the partial contribution of each Cupressaceae species to the airborne pollen spectrum cannot be determined (Galán et al. 1998). Pollination usually occurs in late winter or spring but may occur anytime from late summer to early winter for some species of Juniperus (Bikarma et al. 2018).

In Europe, Cupressaceae causes considerable presence of pollen grains during the winter, which makes this type of pollen the most abundant in this period of the year (Cabrera and Subiza 2008). Particularly for the western Mediterranean area, it is extended from October to April and, in general, maxima are reached in February and March (Bousquet et al. 1984; Caiaffa et al. 1993; Subiza et al. 1998). Seed maturation occurs in late summer or autumn (Watson and Eckenwalder 1993). Pollen release patterns reflect plant phenology, which is in turn affected by climatic factors, such as temperature (especially in trees) and relative humidity (especially in herbaceous plants) as reported by Pace et al. (2017). In winter, its pollen stands out since there is no high count of other species. Generally, pollen counts are carried out in a common way for all genera of the Cupressaceae and Taxaceae family (Hidalgo et al. 2003; Pace et al. 2017).

Studies on floral phenology for allergenic plants are scarce, and these observations are of great interest and complementary to understand and to study pollen allergy and reproductive biology (Monroy-Colín et al. 2018), being useful to forecast pollen concentrations (Hidalgo et al. 2003; García-Mozo et al. 2008). In this way, it allows to identify the beginning of the emission of allergy-related aerobiological particles and thus alert allergic patients (Katz et al. 2019). The floral phenology includes the direct observation of the flowering of the plants and at the same time through the pollen measurement in the emitted air (Hidalgo et al. 2003; Tormo-Molina et al. 2011).

Thus, although the presence of pollen in the air reflects mainly the composition of the local vegetation (Katz et al. 2019), the dispersion, deposition and consequently the records for pollen grains depend on several factors such as the number of plants in the city and their maturity (Maya-Manzano et al. 2017a), the pollen production per individual (Tormo-Molina et al. 2011; Tormo-Molina et al. 2015) and the meteorology (Hidalgo et al. 2003; Katz et al. 2019). The wind direction pattern is particularly important (Hidalgo 
et al. 2003; Charpin et al. 2017), since it can distort the pollen records transporting pollen from other points within or outside one city (Damialis et al. 2005; MayaManzano et al. 2017b) or by means of resuspension of the particles that had already been deposited (Díaz de la Guardia et al. 2006; Tormo-Molina et al. 2011). Also, likewise, the results can be influenced by the location of the aerobiological samplers within the city, the proximity of the pollen sources and the land use (Maya-Manzano et al. 2017b). Consequently, the assumption that pollen in the air is equivalent to phenology is misleading, particularly in regions with variable climatic conditions (Aboulaich et al. 2008). Day-to-day weather variability can strongly impact this, as can transport (also a direct consequence of a particular weather pattern).

Therefore, the importance of developing field studies and to contrast them with what is observed in the volumetric samplers, especially for the most allergenic species as Cupressaceae family (Díaz de la Guardia et al. 2006; Tormo-Molina et al. 2011). Cupressaceae pollen has been cited as one of the major airborne allergens of the Mediterranean region and in other regions around the world (D'Amato et al. 2007; Charpin et al. 2017). The first reference of allergy caused by this pollen was in Japan (Miyao et al. 1993). Subsequently, reports have appeared, mainly from European countries, Japan and North America, reporting cases of cypress allergy (Charpin et al. 2005 and D'Amato et al. 2007). Burbach et al. (2009) reported clinically relevant sensitization rates of $2.6 \%$ in Europe, reaching rates of $6 \%$ and $8.7 \%$ for Italy and UK. The prevalence of sensitization to Cupressaceae pollen has increased in the last decades due to: (a) a higher exposure due to an overuse and planting of trees (Charpin et al. 2019), (b) the increasing allergenicity of pollen grains due to atmospheric pollutants (Wang et al. 2010; Suarez-Cervera et al. 2008; Okuyama et al. 2007), (c) a proper identification of the allergic disease (confused in the past with winter catarrhal processes) with improved allergenic extracts (Charpin et al. 2019) and (d) due to global warming, the pollination period tends to last longer, and there is a trend for inducing a redistribution of Cupressaceae toward northern areas, leading to the sensitization of more individuals (Charpin et al. 2019). Allergic patients to Cupressaceae pollen have a very high incidence of rhinitis and conjunctivitis, being more severe than in the rest of other pollinosis (Bousquet et al. 1993; Hrabina et al. 2003; Pahus et al. 2018).

The pollination of some of these varieties coincides temporarily, and because there is great cross-reactivity between them, the presence of symptoms is continuous for several months, with onset of peaks outside the station (Lahoz et al. 2003). Cupressaceae is characterized by the dispersion of its pollen when temperatures are mild, while it avoids it when it is cold (Cabrera and Subiza 2008; Díaz de la Guardia et al. 2006; Tormo-Molina et al. 2011). The duration and intensity of the mean pollen season are closely linked to the length of the period registering allergic symptoms. Therefore, winter (with warmer temperature and with more rainfall than usual as it has been in recent years) is favorable to more pollen being released and it favors a higher incidence of symptoms among those affected (Cabrera and Subiza 2008). It is important to study the influence of meteorology on the presence of pollen in the air. There are some studies that indicate that the temperature plays an important role in the presence of pollen grains in the air (Belmonte et al. 1999; Burr 1999; Emberlin et al. 1999; Torrigiani et al. 2007). Díaz de la Guardia et al. (2006) carried out a 7-year study, where they pointed out that the fluctuations found in the duration of the pollination period are directly related to environmental conditions in the period prior, such as rain and temperature; the precipitation during flowering causes excessive prolongation of the season and low pollen intensity; and on the other hand, excessively warm temperatures during pollen production shorten the mean pollen season and prompt high concentrations. According to previous Spanish studies (Galán et al. 1998; Cariñanos et al. 2000; Aira et al. 2001; Tortajada and Mateu 2008 and Silva-Palacios et al. 2016), statistically significant correlation coefficients have been found with thermal parameters, rainfall and relative humidity with the presence of pollen in the air.

Green spaces and urban green infrastructure are new concepts in urban planning, and lately, the influence of green spaces in cities from the point of view of local climate change to the influence on the health of urban areas has been taken into account population, as some of the most used ornamental trees in cities cause allergic symptoms in sensitized people (Maya-Manzano et al. 2017a). Due to the increase in the number of patients with allergies, it is necessary to identify the source of pollen origin and thus improve 
the air quality within cities. Currently, there are some studies about the allergenic potential of some ornamental plants (Velasco-Jiménez et al. 2013; Staffolani et al. 2011); however, none of them identifies, quantifies and georeferences specimens of species with aerobiological interest. In the study area planted as ornamentals appear seven species (Platycladus orientalis, Calocedrus decurrens, Juniperus horizontalis, Cupressocyparis leylandii, Cupressus arizonica, Cupressus macrocarpa and Cupressus sempervirens) (Silva-Palacios et al. 2016). Other related species with similar pollen morphology but with a minimal representation are Taxus baccata, Sequoia sempervirens, Taxodium distichum, Juniperus oxycedrus and Juniperus phoenicea.

The objective of this study is to analyze the relationships of Cupressaceae airborne pollen with the distribution of pollen sources surrounding the sampler considering meteorology and phenology, for a period of 3 years of monitoring in a city of SW Iberian Peninsula.

\section{Materials and methods}

This study has been carried out in Badajoz, a city of Extremadura (SW of Iberian Peninsula) with 150,543 inhabitants (NSI 2018). The city is located $184 \mathrm{~m}$ above sea level and crossed by the Guadiana River with the Gévora River as a tributary. The region has a Mediterranean climate affected by a degree of continentality, with an average annual temperature for Badajoz of $17.1^{\circ} \mathrm{C}$ and an average annual rainfall of $463 \mathrm{~mm}$. The highest temperatures are reached in the summer, mainly in July and August (AEMET 2019).

Trees of Cupressaceae were explored during the period of this study (2016-2018) in Badajoz (SW Iberian Peninsula), counted and georeferenced on a map. Meteorological data were provided by the National Meteorology Agency (AEMET 2019) with the meteorological station located at $38^{\circ} 53^{\prime} 15^{\prime \prime} \mathrm{N}, 7^{\circ}$ $0^{\prime} 29^{\prime \prime} \mathrm{W}$, at $3.75 \mathrm{~km}$ apart from the aerobiological sampler. Moreover, a portable weather station (WSGP1 Delta-T) was located 2 meters apart from the pollen trap (Fig. 1a). While the AEMET meteorological station provided daily data, the portable meteorological station data were recorded every $10 \mathrm{~min}$, including temperature $\left({ }^{\circ} \mathrm{C}\right)$, rain $(\mathrm{mm})$, relative humidity $(\%)$, wind speed $\left(\mathrm{m} \mathrm{s}^{-1}\right)$ and wind direction (degrees), providing data for the last 5 years of the study. To process wind direction data, 10-min values were transformed in $30^{\circ}$ sections (12 values), and these values transformed into hourly data giving the mode as final value. For the rest of meteorological parameters, an average value was used except for rain that sums were calculated (Monroy-Colín et al. 2018).

Cupressaceae pollen grains have been collected using a Burkard 7-day pollen trap (Hirst 1952). The trap was situated at 6-m-height terrace, in the Agricultural Engineering School of the University of Extremadura $\left(38^{\circ} 53^{\prime} \mathrm{N}, 6^{\circ} 58^{\prime} \mathrm{W}\right)$. Standardized data management procedures for capturing and counting airborne pollen were used according to the Spanish Aerobiology Network (REA) (Galán et al. 2007). Pollen records were expressed as the number of pollen grains per cubic meter of air (pollen grains $\mathrm{m}^{-3}$ ), and the MPS was calculated by using the $90 \%$ method, proposed by Nilsson and Persson (1981). Phenology of pollen shedding was studied in 50 specimens for 3 years (2016, 2017 and 2018) during January to March: ten of C. macrocarpa, ten of $C$. arizonica, 15 of C. sempervirens and 15 of Platycladus orientalis with a frequency of 3-4 days on average. In all cases, five specimens in were in the surrounding of pollen station and at least five of them $4 \mathrm{~km}$ apart of the pollen trap. Specimens close to the pollen trap are marked in Fig. 1b.

Phenological phases studied were recorded according to a $\mathrm{BBCH}$ code (Biologische Bundesanstalt, Bundessortenamt, Chemische Industrie) (Meier 1997), an internationally recognized standard in the agricultural sector which classifies plant growth phases according to a standardized system (Meier 2001). For each tree, only in sunny days and with calm winds at noon, pollen shedding was mechanically tested over ten branches at 1.5-2 m height that were touched or shaken. Percentage of pollen shedding was recorded from beginning of flowering with $10 \%$ of open flowers (BF, BBCH 61) up to full flowering (FF, $\mathrm{BBCH} 65$, general flowering or full blossom) when approximately at least $50 \%$ of the flowers are open. This methodology has been also previously used in other previous works (Monroy-Colín et al. 2018).

After the normality analysis by using the Kolmogorov-Smirnov test, nonnormality was found, and the Spearman's rank coefficient test was used to analyze the correlation between pollen concentration and meteorological parameters (temperature, rain, 


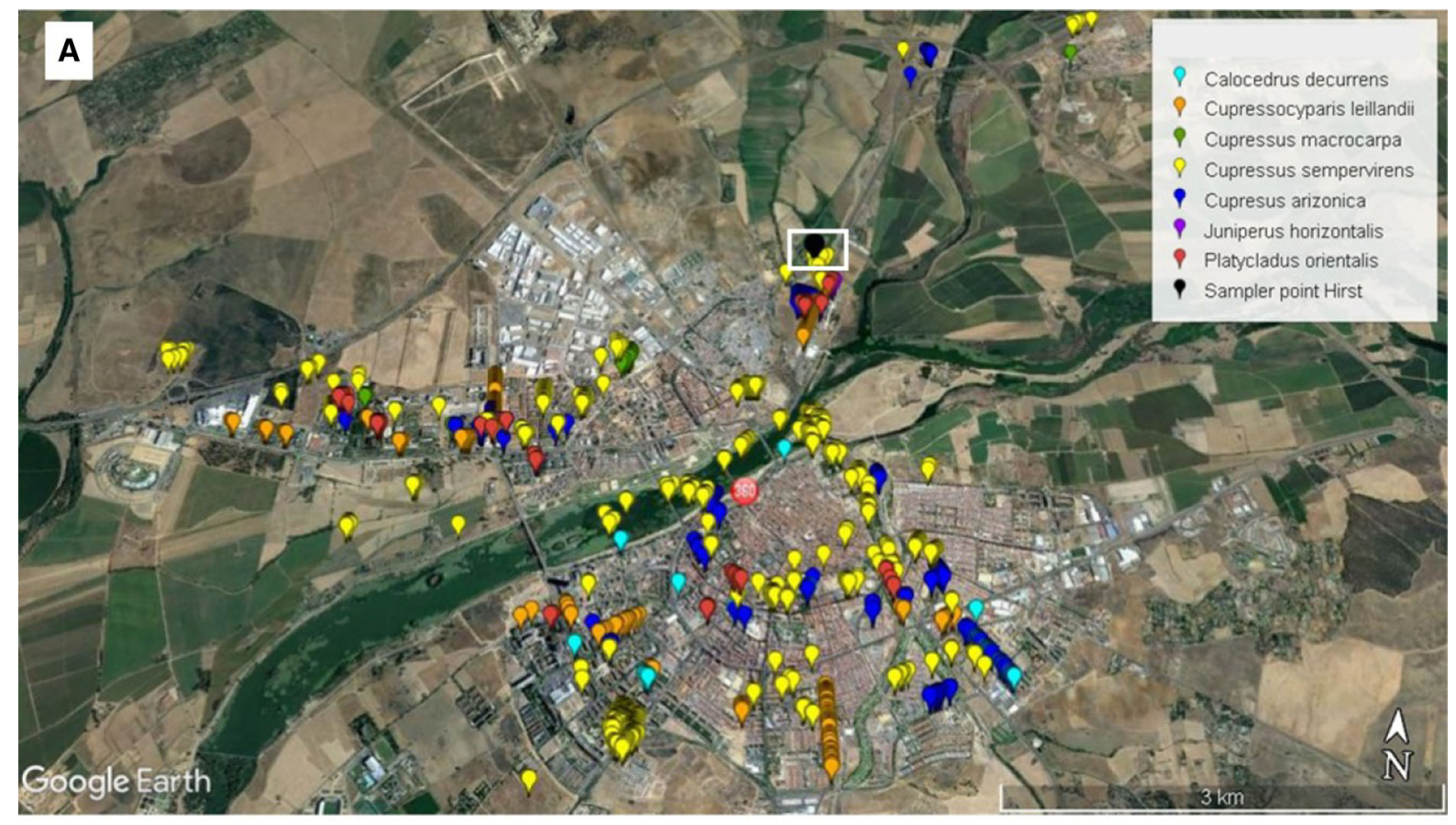

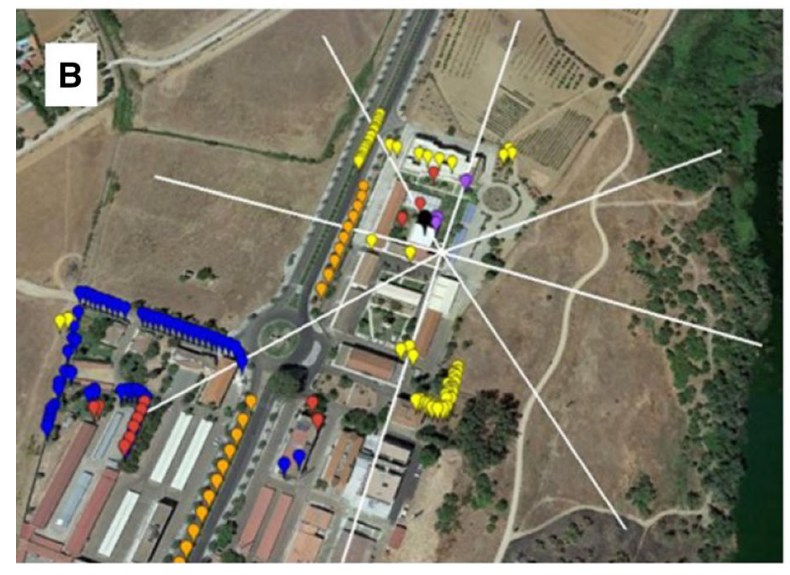

Fig. 1 a Geolocation of Cupressaceae trees. b Pollen trap location and distribution of the surrounding Cupressaceae trees. C. sempervirens (yellow dots), C. arizonica (blue dots), $P$. orientalis (red dots). Phenologically studied trees with encircled

relative humidity, wind direction and wind speed). To analyze at what temperature is recorded most pollen, a graphical analysis was performed summing daily pollen concentration for each average temperature. The statistical analysis was performed with the SPSS 22 statistical package.

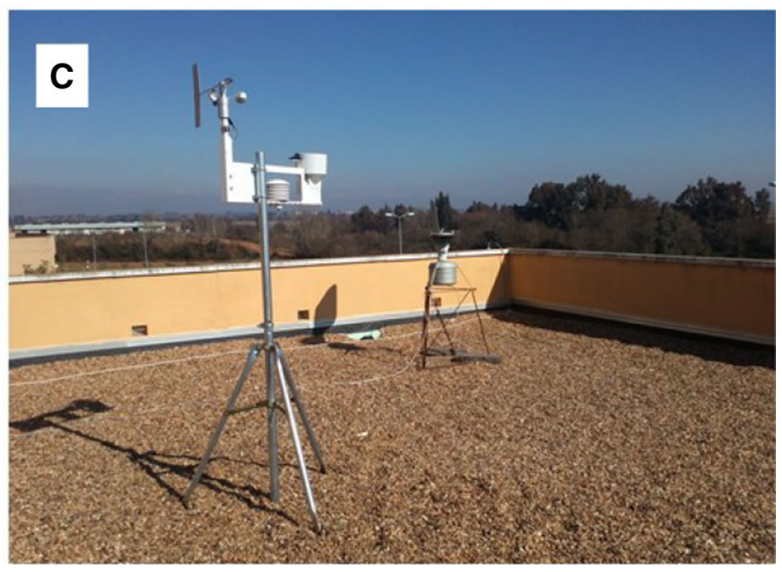

dots were counted separately according to sections of 30 degrees surrounding the pollen trap. $\mathbf{c}$ Pollen trap and portable weather station (WS-GP1 Delta-T)

\section{Results}

In Badajoz, there were geolocalized a total of 1275 trees or shrubs belonging to the Cupressaceae family (Fig. 1a). The most abundant species are C. sempervirens (54\%), C. arizonica (17\%), P. orientalis (8\%) and $C$. macrocarpa (2\%). Figure 1 shows the pollen trap location and distribution of the surrounding Cupressaceae trees; a total of 150 trees were counted 
within a circle $500 \mathrm{~m}$ in diameter surrounding the pollen trap (Fig. 1b). They were counted separately according to sections of 30 degrees surrounding the pollen trap. This area was selected because most of the trees surrounding the pollen trap were in this area, and some previous studies had also been conducted in this area (Monroy-Colín et al. 2018). Most of the trees were located toward the southwest (Table 1). Flowering began in the last week of January and ended in the third week of March. The maximums are presented with a maximum in the third week of February (Fig. 2). The average duration of the flowering period was 38 days (Tables 2 and 3). The phenological observations of species studied indicate that pollination was carried out for 76 days always within the period of airborne pollen records; however, pollen records outside the phenological observations represent $13.3 \%$. The $0.6 \%$ of pollen was detected before and $12,7 \%$ pollen afterward (Tables 2, 3). The phenological observations indicate that the chronological order of pollen release is $P$. orientalis, $C$. arizonica, $C$. macrocarpa and $C$. sempervirens (Table 2). In 2016 and 2017, the maximum pollen concentration matched with the phenology period of three out of the four species (P. orientalis, C. arizonica and $C$. macrocarpa); however, in 2018, the maximum pollen concentration occurred after the phenology period (Table 2).

Table 1 Number of Cupressaceae trees within a circle of $500 \mathrm{~m}$ diameter from the pollen trap every $30^{\circ}$

\begin{tabular}{lccl}
\hline Degrees & C. sempervirens & C. arizonica & P. orientalis \\
\hline $0-29$ & 3 & 0 & 0 \\
$30-59$ & 3 & 0 & 0 \\
$60-89$ & 0 & 0 & 0 \\
$90-119$ & 0 & 0 & 0 \\
$120-149$ & 30 & 0 & 0 \\
$150-179$ & 2 & 0 & 0 \\
$180-209$ & 0 & 2 & 2 \\
$210-239$ & 0 & 42 & 0 \\
$240-269$ & 3 & 34 & 0 \\
$270-299$ & 0 & 0 & 0 \\
$300-329$ & 15 & 0 & 1 \\
$330-360$ & 12 & 0 & 1 \\
Total & 68 & 78 & 4 \\
\hline
\end{tabular}

In 2016, daily peak maximum pollen concentration reached 121 pollen grains $\mathrm{m}^{-3}$ (February 06) (Fig. 3a) Pollination period was from January 01 to April 03, with a maximum values occurring on January $22(P$. orientalis) (Fig. 3b), February 17 (C. arizonica) (Fig. 3c) and February 25 (C. macrocarpa and $C$. sempervirens) (Fig. 3d, e); pollen records outside this period represent $12.7 \%$ (Table 3; Fig. 3f). The maximum pollen concentration coincides with the phenology period of three of the four species ( $P$. orientalis, $C$. arizonica and C. macrocarpa).

For 2017, daily peak maximum pollen concentration reached 606 pollen grains $\mathrm{m}^{-3}$ (February 14) (Fig. 4a). Pollination period was from January 09 to April 07, with a maximum reached on January $31(P$. orientalis) (Fig. 4b), February 11 (C. arizonica) (Fig. 4c), February 17 and 24 (C. macrocarpa) (Fig. 4d) and February 17 (C. sempervirens) (Fig. 4e). Pollen records outside this period represent $4.61 \%$ (Table 3; Fig. 4f).

In 2018, daily peak maximum pollen concentration reached 334 pollen grains $\mathrm{m}^{3}$ (09/03) (Fig. 5a). Pollination period occurred from January 09 to April 07 , with a maximum values occurring on January 24 ( $P$. orientalis) (Fig. 5b), February 23 and 26 ( $C$. arizonica) (Fig. 5c) and February 26 (C. macrocarpa and $C$. sempervirens) (Fig. $5 \mathrm{~d}$, e); pollen records outside this period represent $7.38 \%$ (Table 3; Fig. 5f).

Table 4 and Fig. 6 show the annual pollen integral for the 3 years and the hourly concentration for the period more deeply analyzed for 2016 (Fig. 6a), 2017 (Fig. 6b) and 2018 (Fig. 6c). In the 3 years, the highest average concentrations were found in the noon, finding a correlation with the increase of temperature and the decrease of humidity in the atmosphere. Figure 7 and Table 5 show the frequency of wind direction. The highest concentrations appeared when the winds are predominantly from SW for the second and third years of the study; nevertheless, in the first year were from the NW the predominant winds. Airborne pollen records showed similar results.

\section{Discussion}

Cupressaceae pollen was detected in Badajoz's atmosphere all through the years. The dates of flowering of Cupressaceae in the city of Badajoz are in line with 


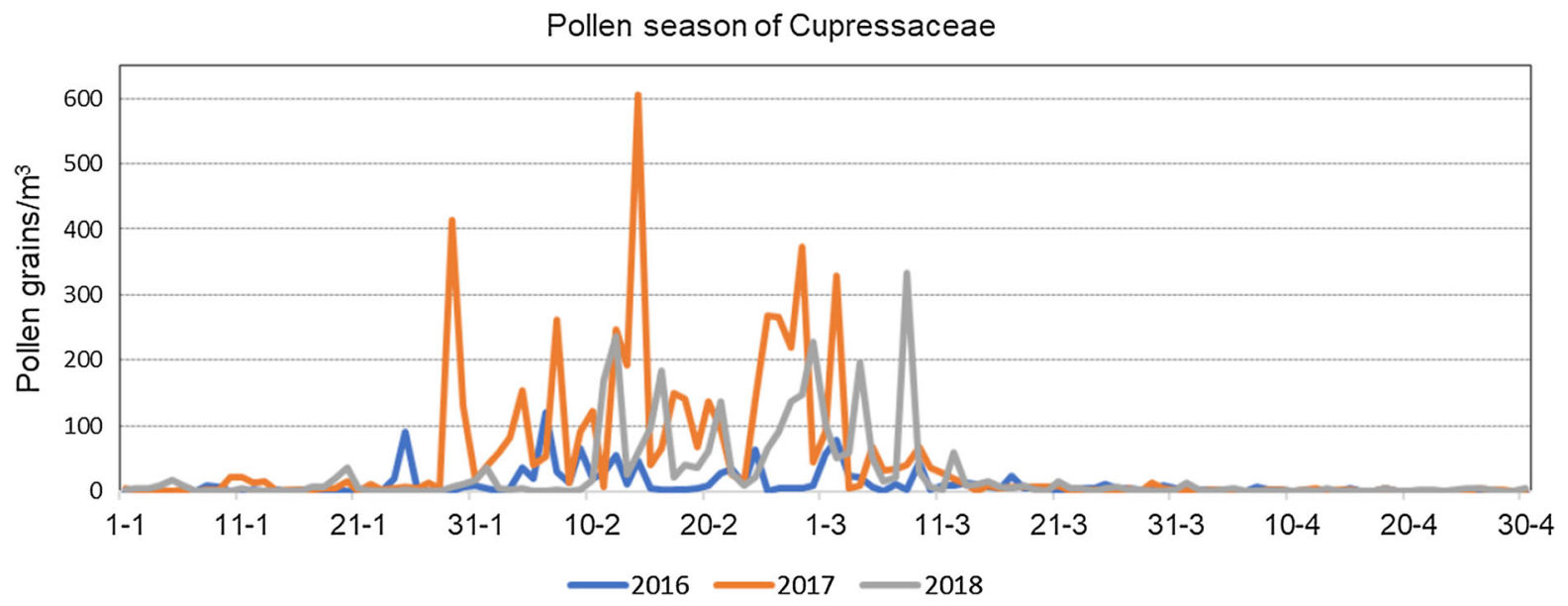

Fig. 2 Pollen season of Cupressaceae 2016-2018

Table 2 Pollination phenology of phenology of Cupressaceae (2016-2018)

\begin{tabular}{|c|c|c|c|c|c|c|c|c|c|}
\hline & \multicolumn{3}{|l|}{2016} & \multicolumn{3}{|l|}{2017} & \multicolumn{3}{|l|}{2018} \\
\hline & $\begin{array}{l}\text { Length } \\
\text { (days) }\end{array}$ & $\begin{array}{l}\text { Peak } \\
\text { day }\end{array}$ & $\begin{array}{l}\text { Duration of } \\
\text { flowering } \\
\text { (days) }\end{array}$ & $\begin{array}{l}\text { Length } \\
\text { (days) }\end{array}$ & $\begin{array}{l}\text { Peak } \\
\text { day }\end{array}$ & $\begin{array}{l}\text { Duration of } \\
\text { flowering } \\
\text { (days) }\end{array}$ & $\begin{array}{l}\text { Length } \\
\text { (days) }\end{array}$ & $\begin{array}{l}\text { Peak } \\
\text { day }\end{array}$ & $\begin{array}{l}\text { Duration of } \\
\text { flowering } \\
\text { (days) }\end{array}$ \\
\hline C. arizonica & $\begin{array}{l}01 / \\
02-16 / \\
03\end{array}$ & $17 / 02$ & 45 & $\begin{array}{l}\text { 28/ } \\
01-06 / \\
03\end{array}$ & $11 / 02$ & 38 & $\begin{array}{l}10 / \\
02-12 / \\
03\end{array}$ & $\begin{array}{l}23 / 02 \\
\text { and } \\
26 / 02\end{array}$ & 31 \\
\hline C. macrocarpa & $\begin{array}{l}\text { 29/ } \\
01-16 / \\
03\end{array}$ & $25 / 02$ & 48 & $\begin{array}{l}10 / \\
02-17 / \\
03\end{array}$ & $\begin{array}{l}\text { 17/02 } \\
\text { and } \\
24 / 02\end{array}$ & 36 & $\begin{array}{l}\text { 20/ } \\
02-12 / \\
03\end{array}$ & $26 / 02$ & 22 \\
\hline $\begin{array}{l}\text { C. } \\
\quad \text { sempervirens }\end{array}$ & $\begin{array}{l}08 / \\
02-23 / \\
03\end{array}$ & $25 / 02$ & 45 & $\begin{array}{l}06 / \\
02-13 / \\
03\end{array}$ & $17 / 02$ & 36 & $\begin{array}{l}15 / \\
02-23 / \\
03\end{array}$ & $26 / 02$ & 37 \\
\hline $\begin{array}{c}\text { Platycladus } \\
\text { orientalis }\end{array}$ & $\begin{array}{l}\text { 08/ } \\
01-10 / \\
02\end{array}$ & $22 / 01$ & 34 & $\begin{array}{l}04 / \\
01-10 / \\
02\end{array}$ & $31 / 01$ & 38 & $\begin{array}{l}08 / \\
01-23 / \\
02\end{array}$ & 24/01 & 47 \\
\hline
\end{tabular}

Table 3 Pollen season of Cupressaceae 2016-2018, data obtained with volumetric trap type Hirst

\begin{tabular}{llcll}
\hline & Pollen season & \multicolumn{2}{l}{ Peak calendar day } & Total days \\
\cline { 3 - 4 } & & Day & Pollen grains $~^{-3}$ & \\
\hline 2016 & $01 / 01-03 / 04$ & $06 /$ & 121 & 94 \\
& 02 & & 89 \\
2017 & $09 / 01-07 / 04$ & $14 /$ & 606 & 89 \\
2018 & $09 / 01-07 / 04$ & $09 /$ & 334 & \\
\hline
\end{tabular}

Cabrera and Subiza (2008) and Silva-Palacios et al. (2016). They pointed out that pollination in Spain occurs from October to April. Although most of the pollen is collected during the first quarter of the year, it coincides with the reported by Hidalgo et al. (2003), who indicated that in Córdoba, $95 \%$ of the pollen shed happened during the first 3 months of the year (Guerra et al. 1996; Hidalgo et al. 2003). This result matched the end of winter and start of spring, finding that the main peak occurred approximately between the end of February and the beginning of March. Several authors have recorded that February is the most important 

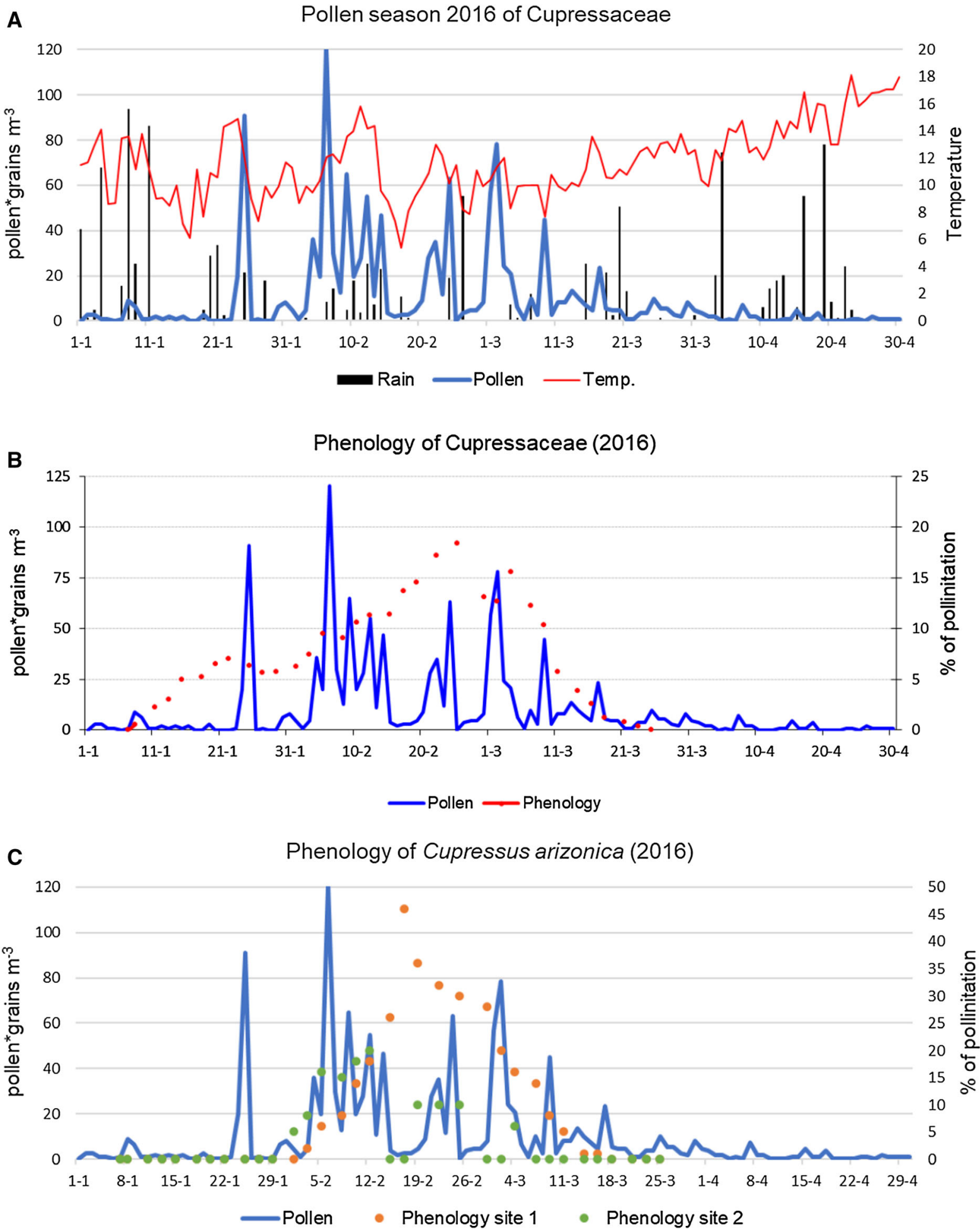

Fig. 3 Pollen season and pollination phenology of Cupressaceae 2016. a Pollen season. b Pollination phenology of $P$. orientalis. $\mathbf{c}$ Pollination phenology of $C$. arizonica. d Pollination phenology of $C$. macrocarpa. e Pollination phenology of $C$. sempervirens. f Pollination phenology 2016 
D

Phenology of Cupressus macrocarpa (2016)

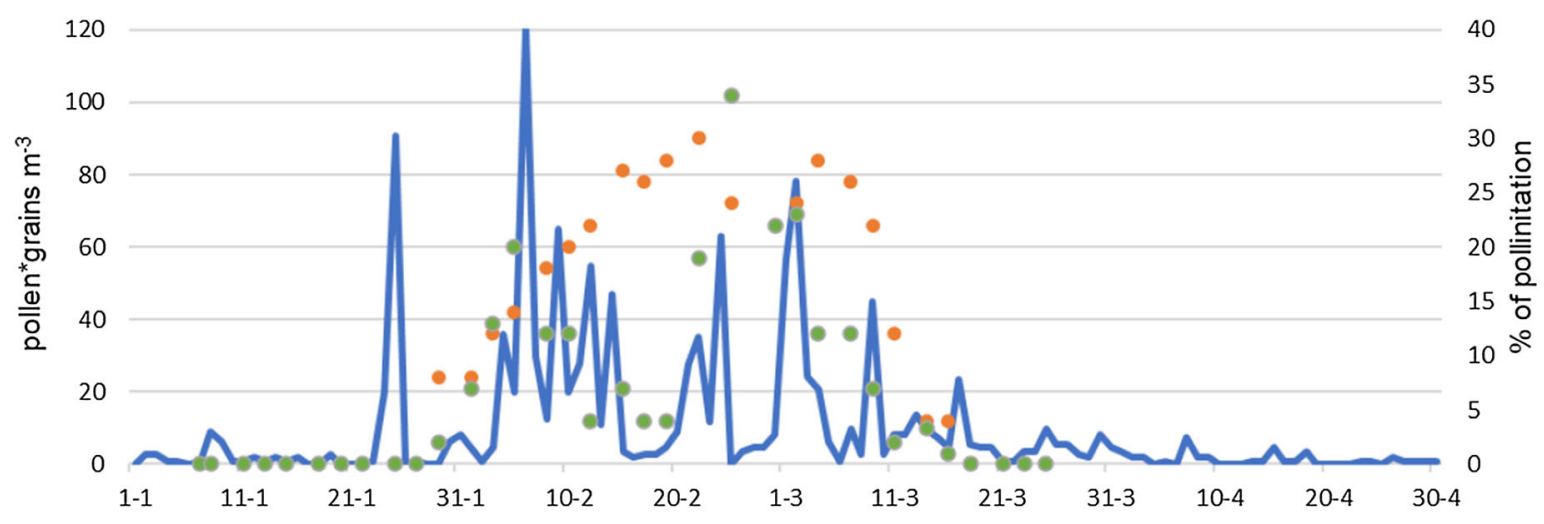

CPollen Phenology site 1 - Phenology site 2

E

Phenology of Cupressus sempervirens (2016)

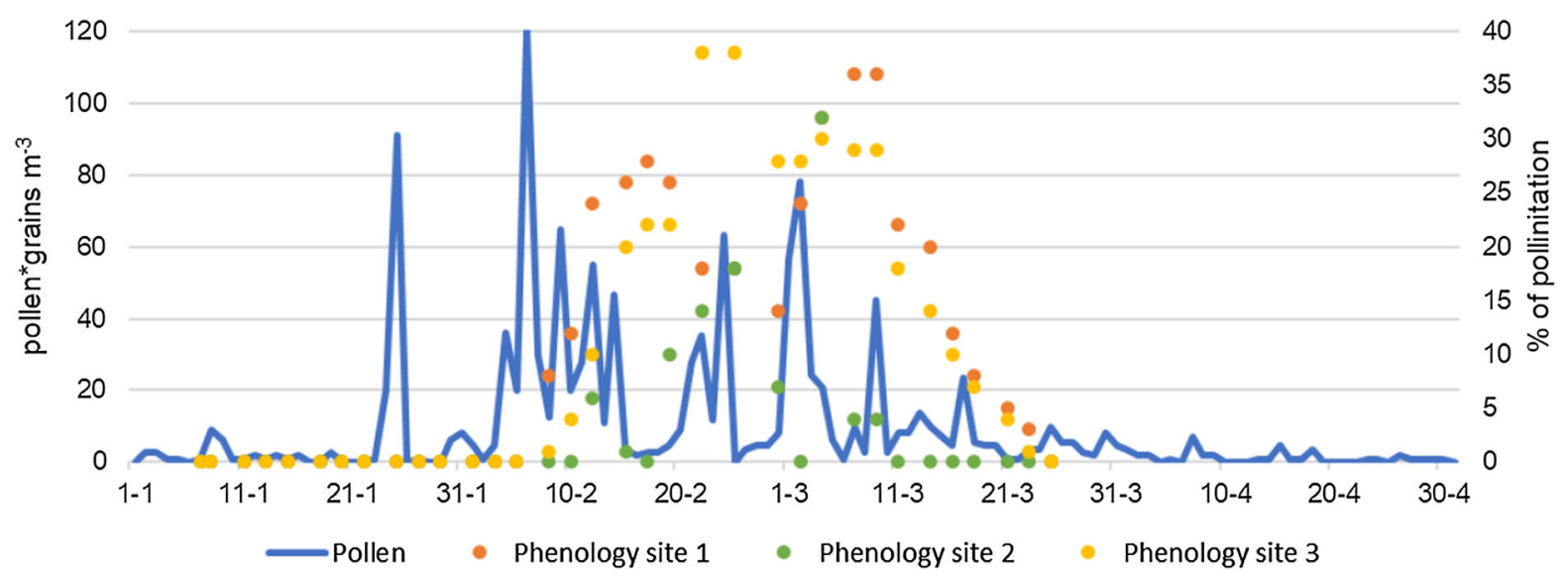

F Phenology of Platycladus orientalis (2016)

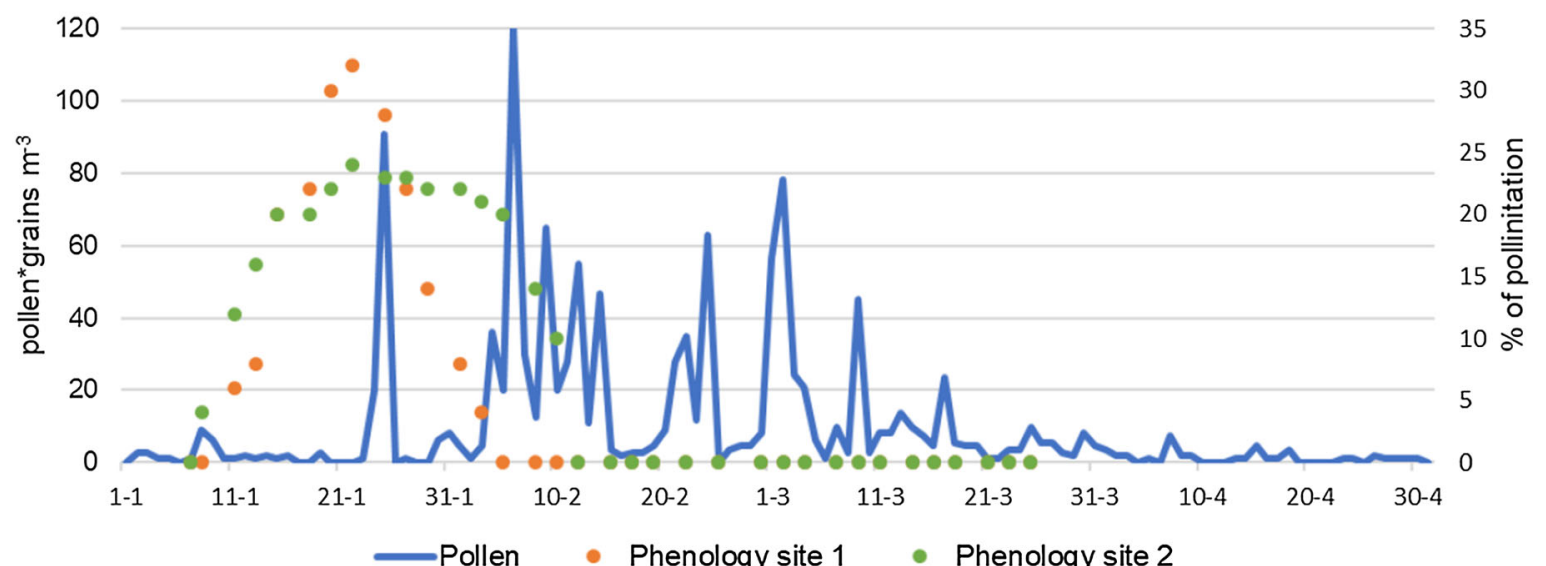

Fig. 3 continued 

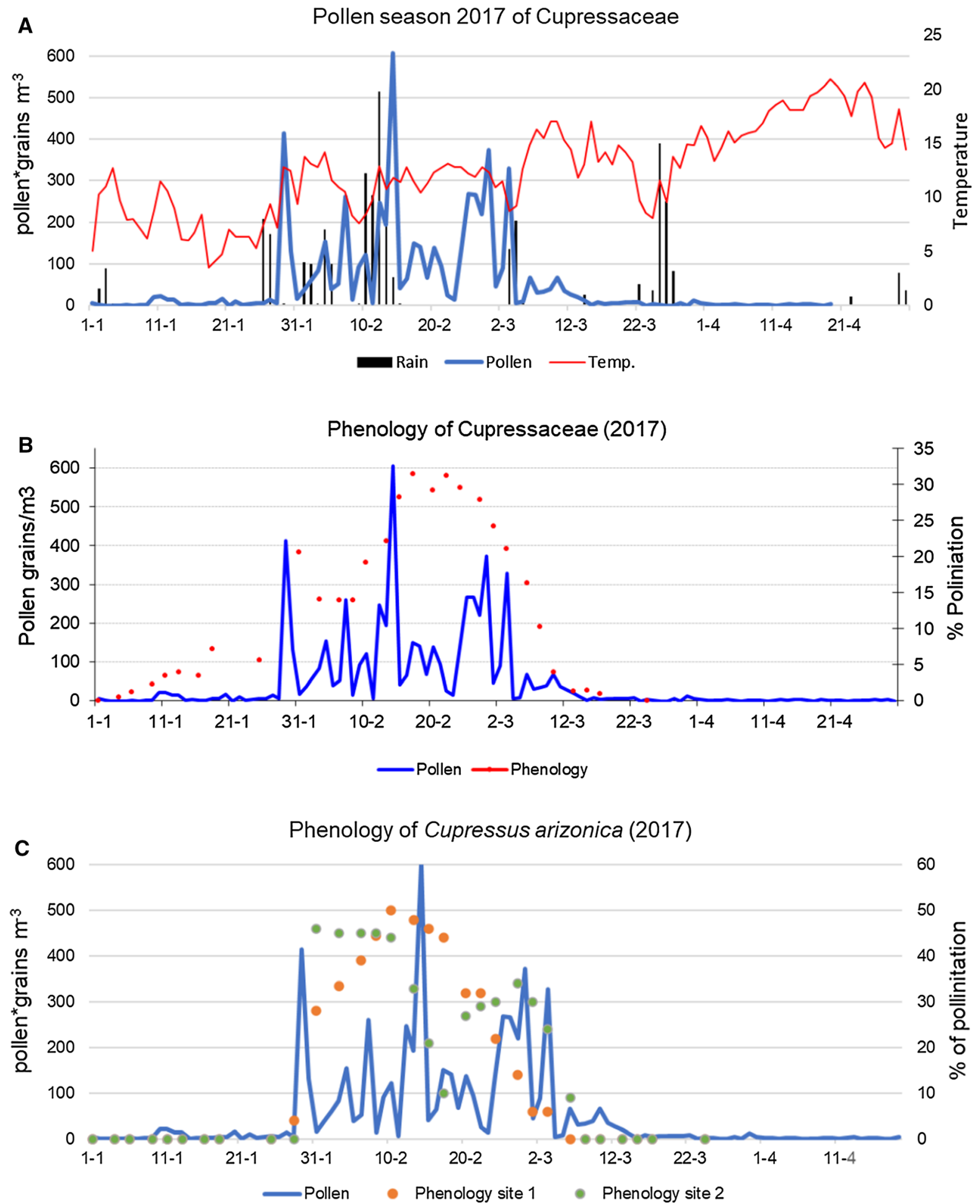

Fig. 4 Pollen season and pollination phenology of Cupressaceae 2017. a Pollen season. b Pollination phenology of $P$. orientalis. $\mathbf{c}$ Pollination phenology of $C$. arizonica. d Pollination phenology of $C$. macrocarpa. e Pollination phenology of $C$. sempervirens. f Pollination phenology 2017 
D Phenology of Cupressus macrocarpa (2017)

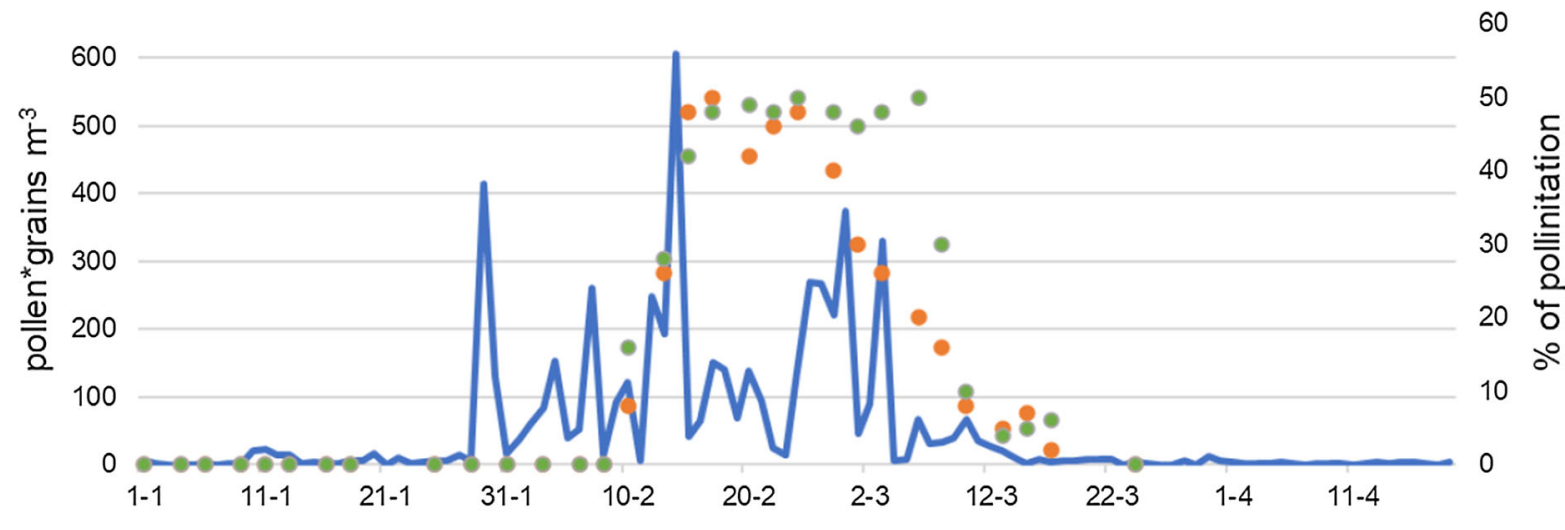

-Pollen Phenology site 1 - Phenology site 2

Phenology of Cupressus sempervirens (2017)
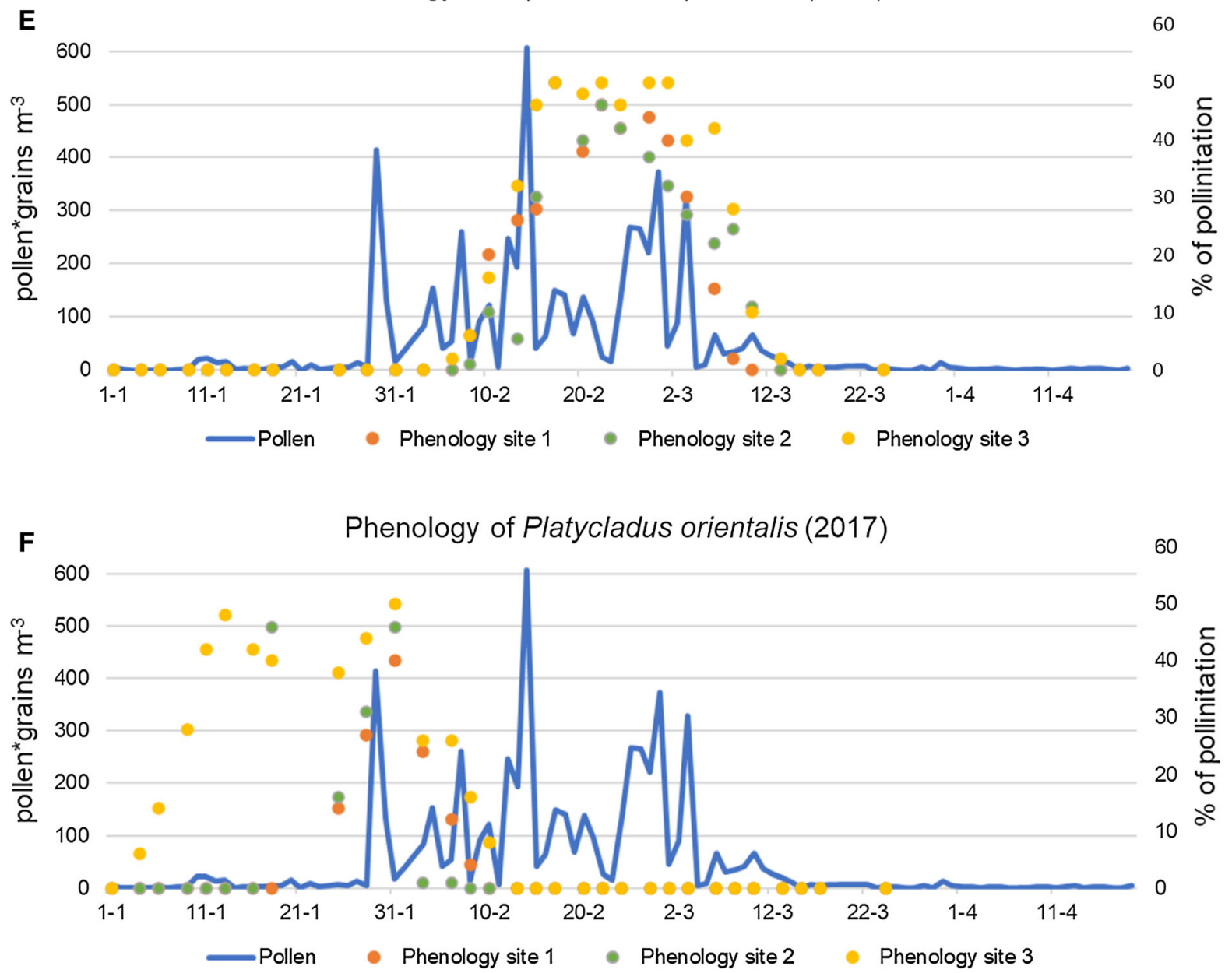

Fig. 4 continued 
A Pollen season of Cupressaceae (2018)

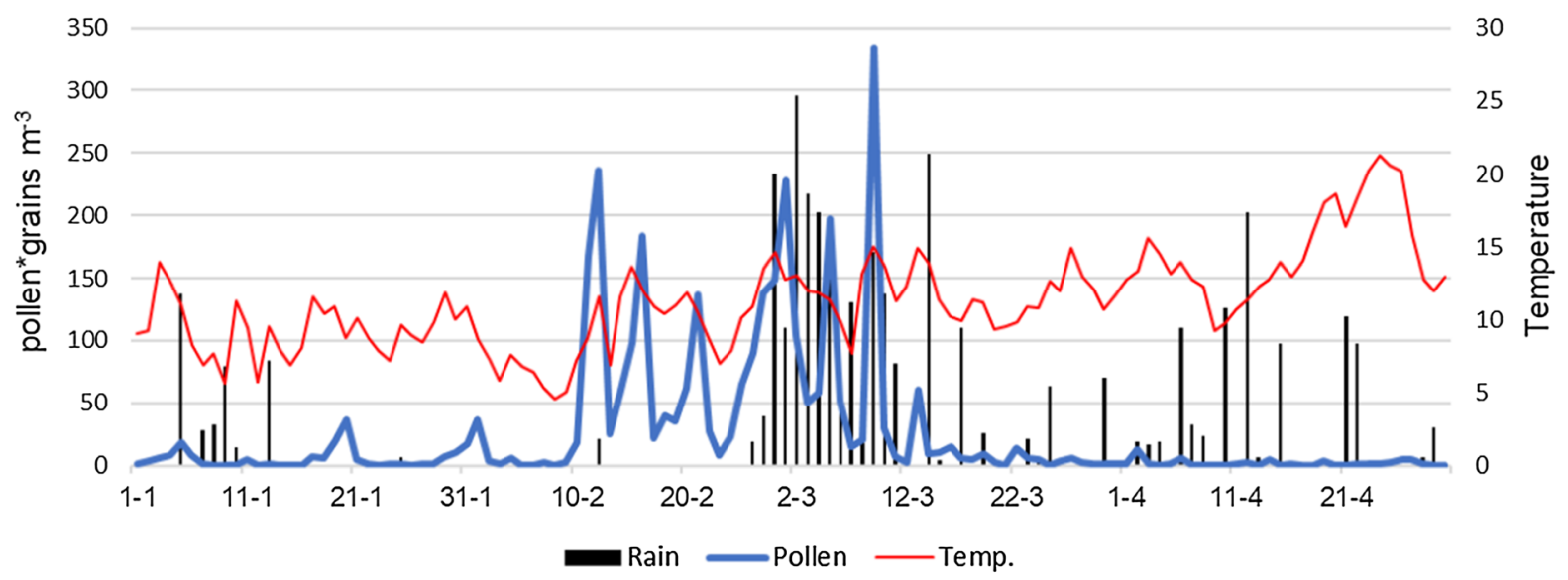

Cupressaceae 2018

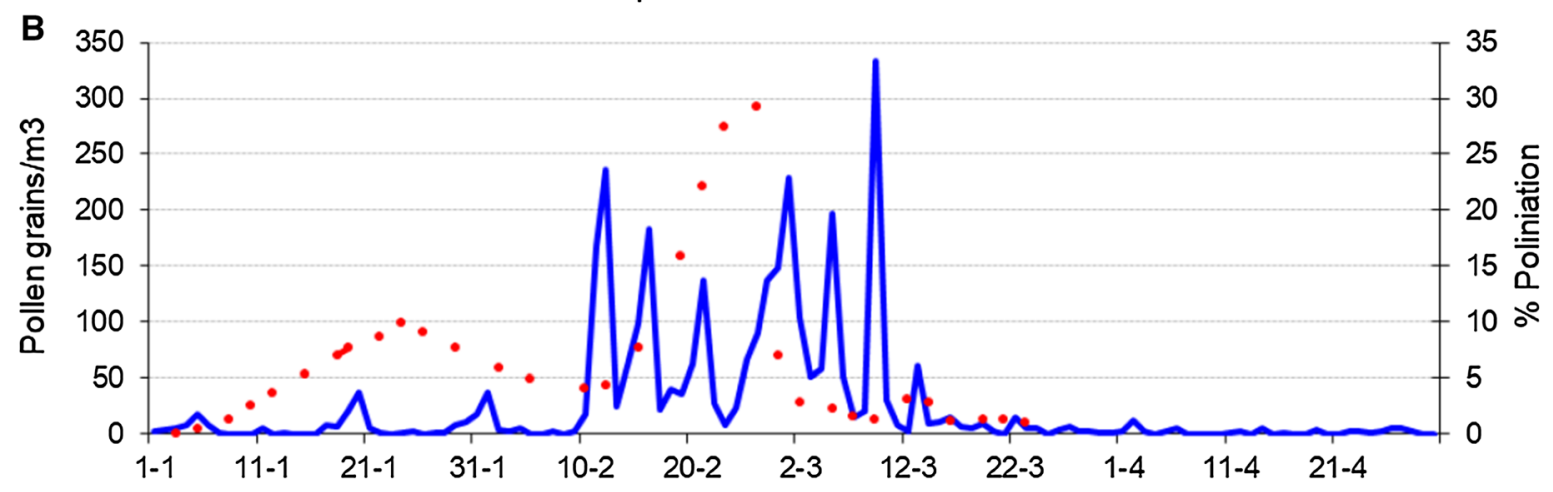

Pollen Phenology

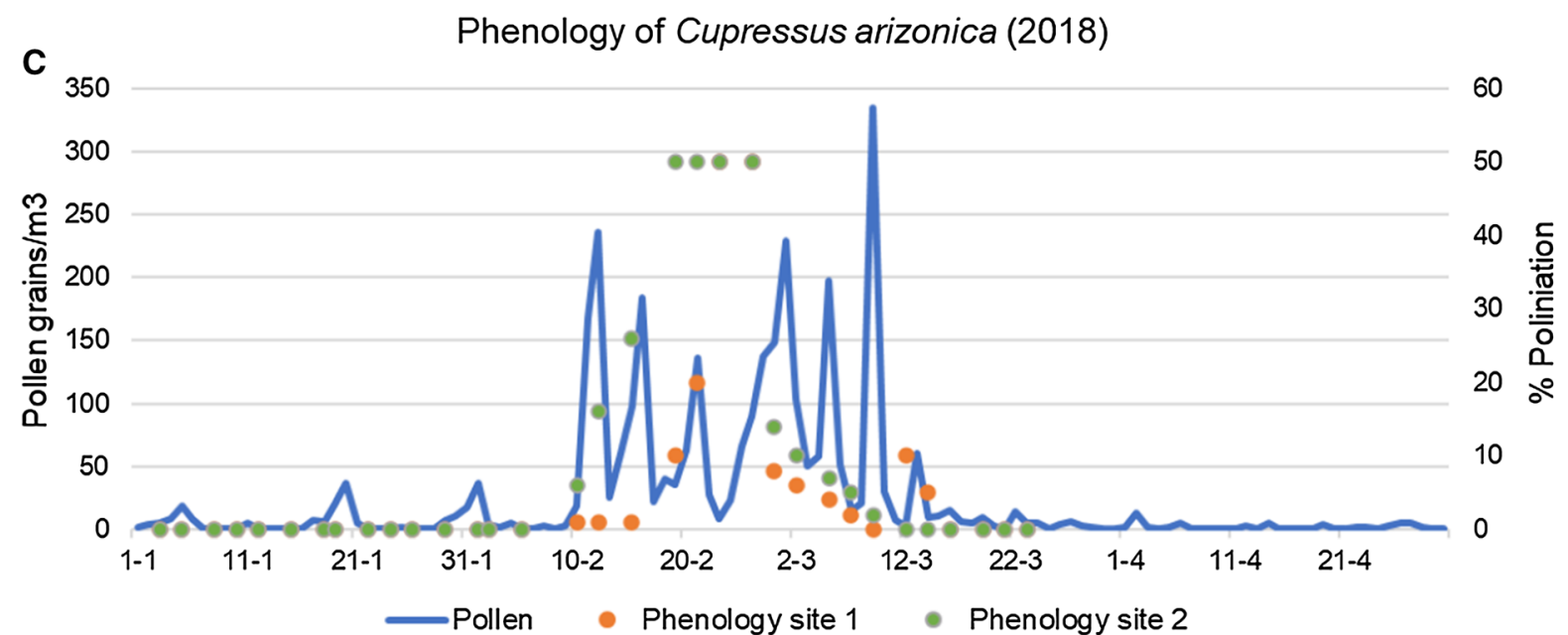


४Fig. 5 Pollen season and pollination phenology of Cupressaceae 2018. a Pollen season. b Pollination phenology of $P$. orientalis. c P Pollination phenology of C. arizonica. d Pollination phenology of C. macrocarpa. e Phenology of C. sempervirens. f Pollination phenology 2018

month to release this kind of pollen grains, with peaks of between 400 and 1000 pollen grains $\mathrm{m}^{-3}$ (Caballero et al. 1996; Hidalgo et al. 2003; Moral de Gregorio 2003; Cabrera and Subiza 2008). Rodríguez-Rajo et al. (2003) reported similar records for Lugo with 268 pollen grains $\mathrm{m}^{-3}$ in March and 213 pollen grains $\mathrm{m}^{-3}$ in January. There are reports for Málaga (Recio et al. 1998) of the appearance of a second peak toward the end of summer and early fall; however, in none of the 3 years of our study, this second peak appeared, or at least it is not remarkable. In our study, values were slightly lower, except for 2017 that was the year with the highest amount of Cupressaceae pollen in the air with 606 pollen grains $\mathrm{m}^{-3}$. However, these data are below the maximum averages of the last decades recorded by Moral de Gregorio (2003). The duration of the main pollen season for Badajoz was on average 91 days, which coincides with that reported for the south of Spain for Cupressaceae by Belmonte et al. (1999), Silva-Palacios et al. (2016) and Tormo-Molina et al. (2011).

In 2017, the opening of flowers was 1 week ahead, compared to the other years. Cupressaceae, like other families, is characterized by its pollen release when temperatures are mild, while they avoid doing it when conditions are cold (Cabrera and Subiza 2008). The temperature plays a very important role in the flowering process, with studies showing that in the coldest years the flowering period is shorter (Tedeschini et al. 2006). On the contrary, during the warmer years, the buds break earlier and the flowering and the release of pollen are given gradually; this phenomenon could explain the difference in the beginning and duration of flowering in the year 2017 (Tedeschini et al. 2006; Cabrera and Subiza 2008).

The chronological order in the phenology coincides in the 3 years of study with that reported for the city of Córdoba; it is recorded that $C$. arizonica flowers about 2 weeks before, while $C$. macrocarpa and C. sempervirens bloom almost simultaneously, the first blooming a little bit earlier (Hidalgo et al. 2003). Trees of different species of the genus Cupressus show a distinct male phenological behavior. Pollen release in C. arizonica always takes place roughly 3 weeks earlier than in the other species. Similar findings were reported by Zerboni et al. (1991) for this species in Florence, Italy, and by Hidalgo et al. (2003) in Córdoba, Spain. They also found that $C$. macrocarpa was the main pollen source in their study, being moreover the most abundant pollen coincident with the phenology period, like in our case (Table 2). Considering the duration of the phenology period and the characteristic of the plant as ornamental, there was a correspondence between the airborne pollen peaks and its phenology, we can assume that for our study, $C$. sempervirens was possibly the main source of the captured airborne pollen. In addition, we must consider that some pollen recorded in the trap is not directly related to the immediate surroundings, because they can be moved from other parts of the city. There are studies that show the importance of long-distance transport as reported by Tormo-Molina et al. (2011) for Spain and Torrigiani et al. (2006) for Italy. They also consider that airborne pollen grains captured outside the pollination period at the sites studied probably came partly from distant sources and partly from resuspension phenomena after pollination.

Studies from the South of Iberian Peninsula showed a second flowering of $C$. arizonica in Córdoba (Hidalgo et al. 2003) and C. sempervirens in autumnal months in Málaga (Recio et al. 1998), that we have not found in our study. Probably, this difference is due to the weather, since Hidalgo et al. (2003) commented that it is quite different from the conditions in those region; they suggest that the physiology of the trees may trigger the flowering some months before, confusing the temperatures of the end of spring with those registered at the beginning of autumn. The average pollen curve per year of Cupressaceae matches what was reported by Hidalgo et al. (2003), showing a symmetric shape despite being the result of the partial contribution of several species with a different phenology. However, the curve shows also an increase toward the end of the season, due to the flowering of the trees of $C$. sempervirens, which overlaps with the main peak produced by $C$. macrocarpa. Some small peaks before the main peak coincide with the main flowering period of $C$. arizonica. 
D

Phenology of Cupressus macrocarpa (2018)

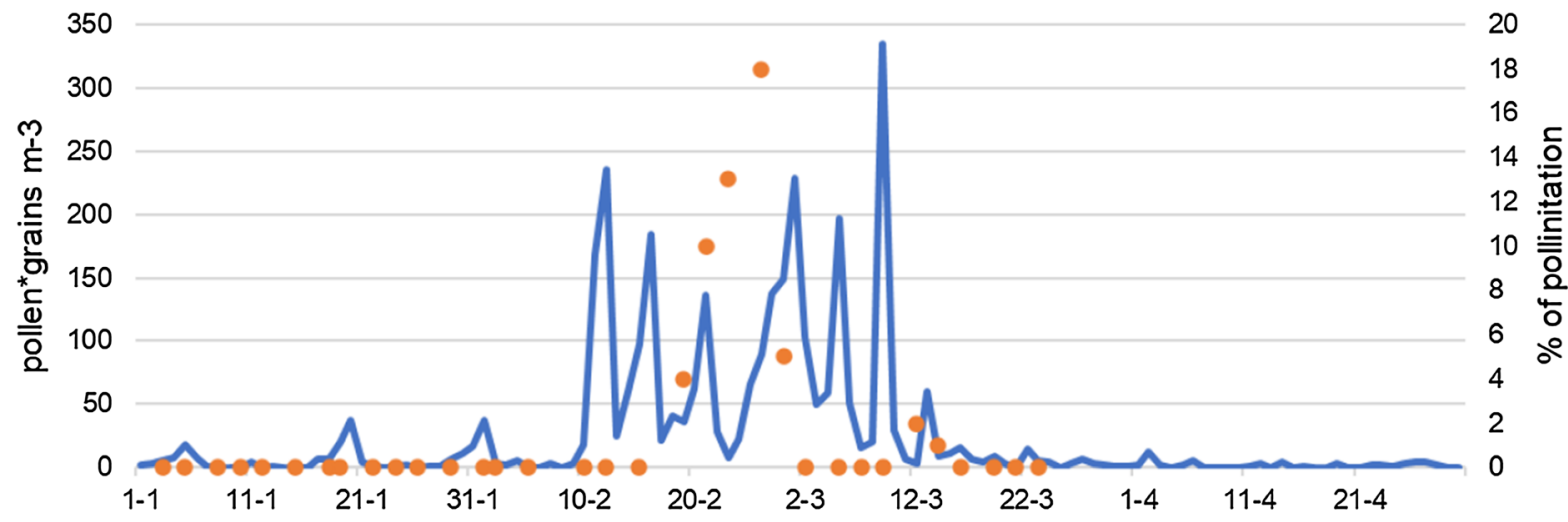

- Pollen Phenology site 1 - Phenology site 2

Phenology of Cupressus sempervirens (2018)

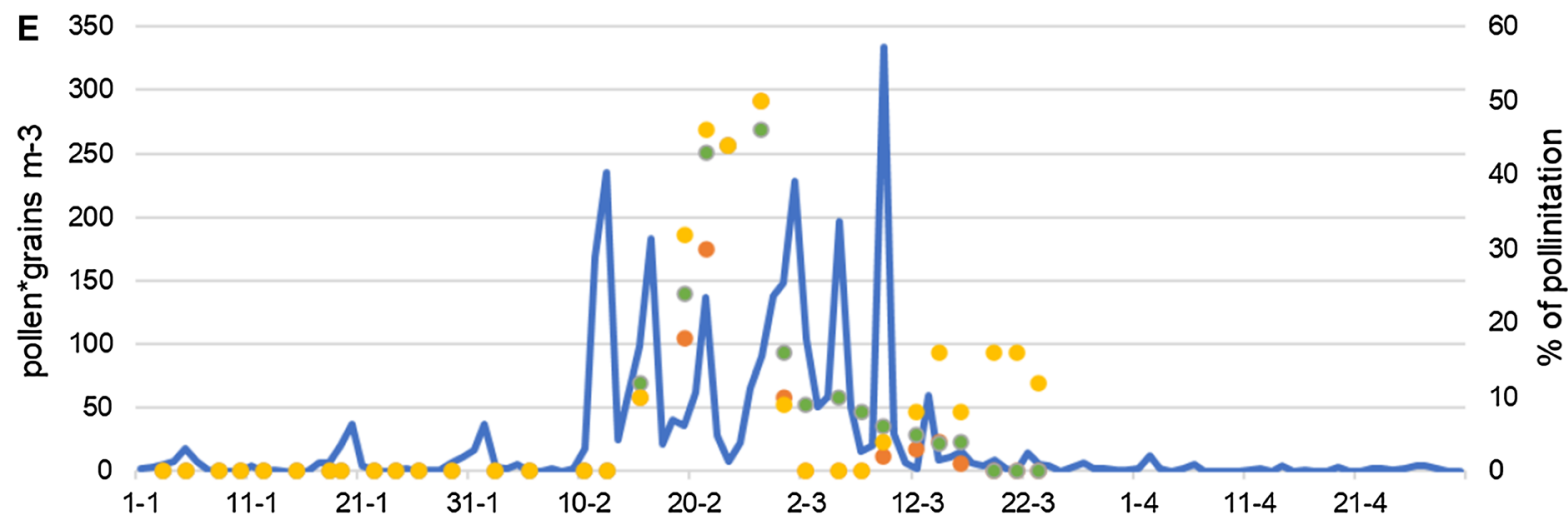

-Pollen Phenology site 1 - Phenology site 2 Phenology site 3

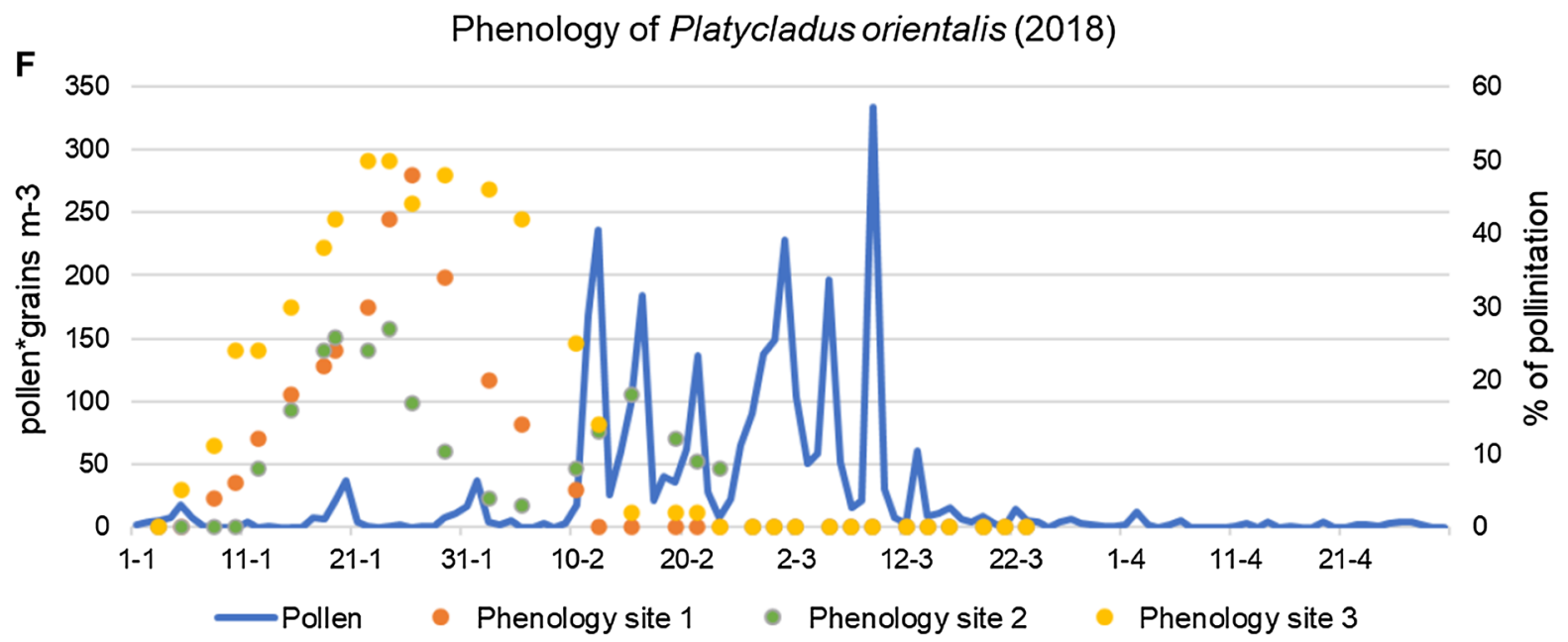

Fig. 5 continued 
Table 4 SPIn (seasonal pollen integral) values, mean pollen season characteristics and Spearman's rank correlation coefficients for daily values of Cupressaceae 2016-2018 with rain (mm), minimum $\left(T_{\min }\right)$, maximum $\left(T_{\max }\right)$ and mean temperature $\left(T_{\text {mean }}\right)$, in ${ }^{\circ} \mathrm{C}$, and wind speed $\left(\mathrm{m} \mathrm{s}^{-1}\right)$

\begin{tabular}{|c|c|c|c|c|c|c|}
\hline & \multicolumn{6}{|l|}{ SPIn } \\
\hline & \multirow[t]{2}{*}{ Pollen grains day $\mathrm{m}^{-3}$} & \multicolumn{5}{|c|}{ Statistically significant correlation } \\
\hline & & Precipitation & $T_{\min }$ & $T_{\max }$ & $T_{\text {mean }}$ & Wind speed \\
\hline 2016 & 1362 & -0.10 & $-0.261 * *$ & 0.0 .73 & 0.13 & $0.21 *$ \\
\hline 2017 & 5857 & 0.10 & 0.07 & $-0.19 *$ & 0.21 & 0.12 \\
\hline 2018 & 3283 & 0.08 & 0.002 & $0.20 *$ & 0.10 & 0.10 \\
\hline
\end{tabular}

*Significance at the $95 \%$ level

**Significance at the $99 \%$ level

There is evidence of long-distance transport of Cupressaceae pollen when sources are abundant in natural vegetation (Water and Levetin 2001; TormoMolina et al. 2011). In terms of hourly data, the highest values appeared between 10:00 and 16:00, and it coincides with that reported by Docampo et al. (2007), by Pérez-Badia et al. (2010) and Fernández-Rodríguez et al. (2014), the last, for the same study area as the present work.

Regarding the meteorological parameters, pollen shedding by the different species of Cupressus is positively correlated with Cupressaceae airborne pollen counts during the three study years. In most cases, the precipitation (and associated moisture) accounts for the lack of coincidence between flowering and the airborne pollen curve. We have found positive correlations with temperature, which agrees with other authors (Frenguelli et al. 1989), whom indicate that correlations with temperature are generally positive, because a drying of the anthers occurs, and dehiscence and release of pollen grains occur, it is important to mention that drying will only occur if relative humidity is also low. On the contrary, when the temperature drops in winter, emission is hampered and the higher humidity and precipitations provoke the aggregation and deposition of the pollen; these results coincide with other aerobiological works (Aira et al. 2001; Norris-Hill and Emberlin 1991). The precipitation (Hall 1992) produces a washing effect in the atmosphere; therefore, it always correlates negatively. Relative humidity should also present negative correlation, if it is present at high levels, because it contributes to increasing the aggregation of pollen grains and increasing the weight and causes the pollen grains to sediment faster (Galán et al. 1989). Also, it could provoke slight delays in the pollen release regarding the pollen availability in the anther, and we have found a negative correlation with the relative humidity; Galán et al. (1989) reports does not affect pollen grains like Cupressaceae with a thin exine.

The high amount of Cupressaceae trees registered in Badajoz, considering their pollen as one of the most allergenic, provides evidence for the creation of risk maps, proper urban planning and design of green spaces in conditions for patients with allergies to this type pollinic and also allows the creation of medical alerts. The analysis of pollen source locations (Fig. 1a) and pollen records according to wind direction reflected a close relationship between the distribution for Cupressaceae trees surrounding the pollen trap and wind transporting airborne pollen, and it coincides with that reported by Tormo-Molina et al. (2013). It is generally accepted that most of the pollen trapped comes from local sources (Solomon and Mathews 1978; Keynan et al. 1991; Damialis et al. 2005). Wind showed a positive correlation with airborne pollen records, as it was highlighted by other authors in the same area (Tormo-Molina et al. 2001). The first study (Tormo-Molina et al. 2001) indicated that in Extremadura, the wind may come from the east (inland in Iberian Peninsula) or from the west (from Portugal); this case had lower temperatures and higher humidity. In our study, the peaks are coincident when the winds are coming from the west, and it is also for this area where the closest pollen production sources are located. In 2016, the direction of the wind was a bit different that those from 2017 and 2018, but the direct influence of wind direction is clear. Our results 

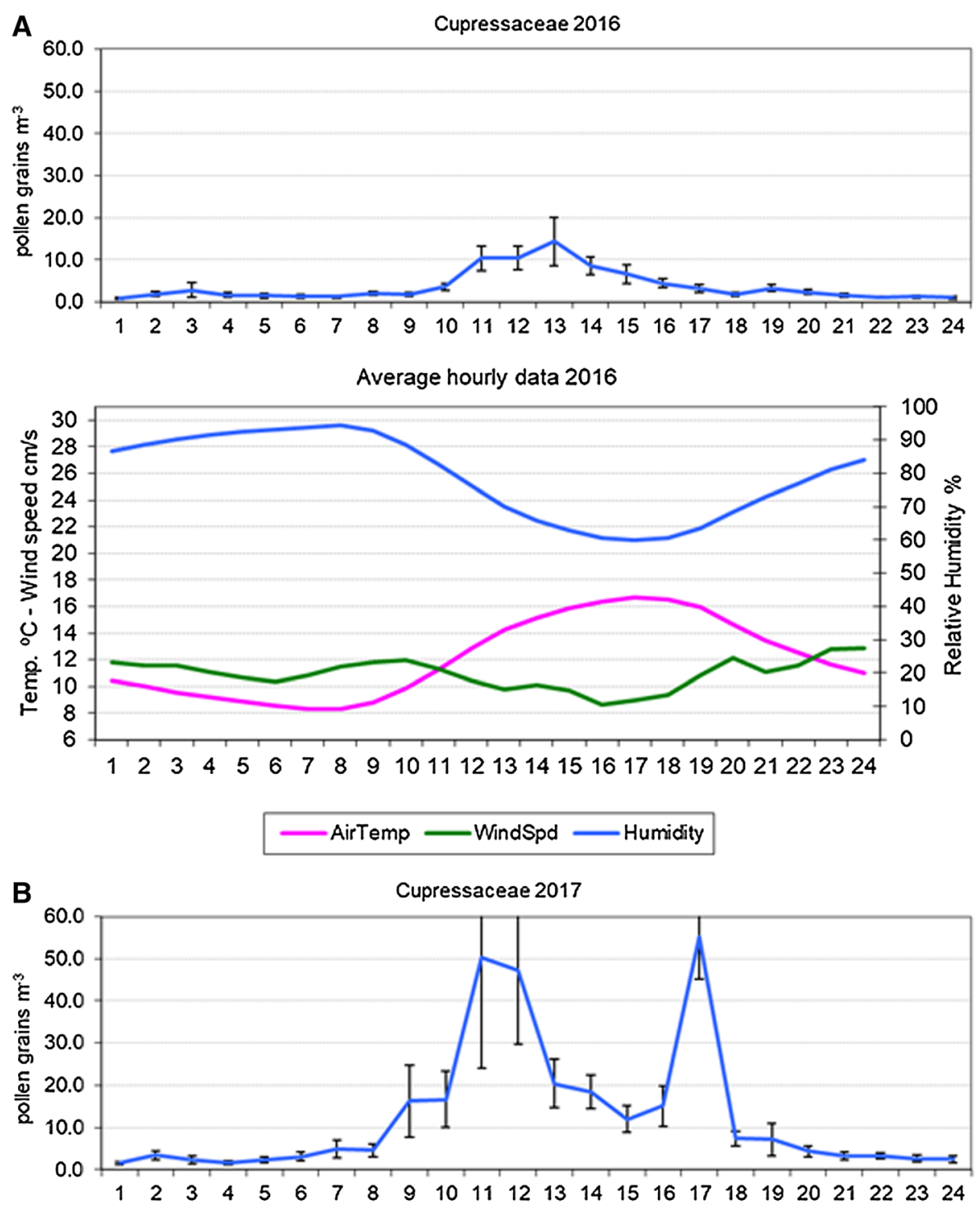

Average hourly data 2017

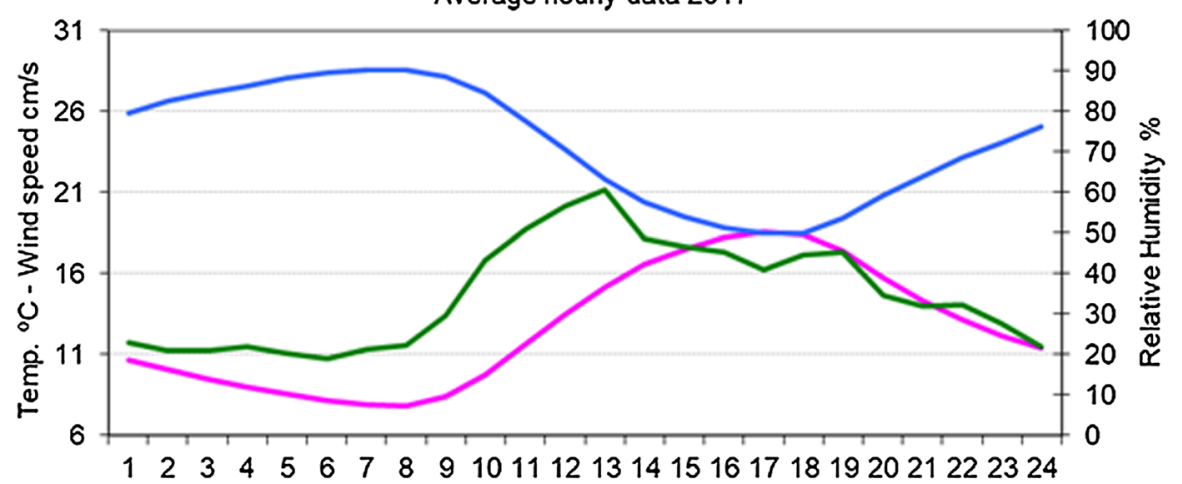

-AirTemp.Avg —WindSpd —Humidity.Avg 
४Fig. 6 Hourly data for Cupressaceae pollen concentration, including error bars, and average meteorological parameters in 2016 (a), 2017 (b) and 2018 (c) coincide with that reported by Damialis et al. (2005), who found a positive correlation on the wind direction and the speed, also mentioning the importance of the persistence of the wind direction in the transport of
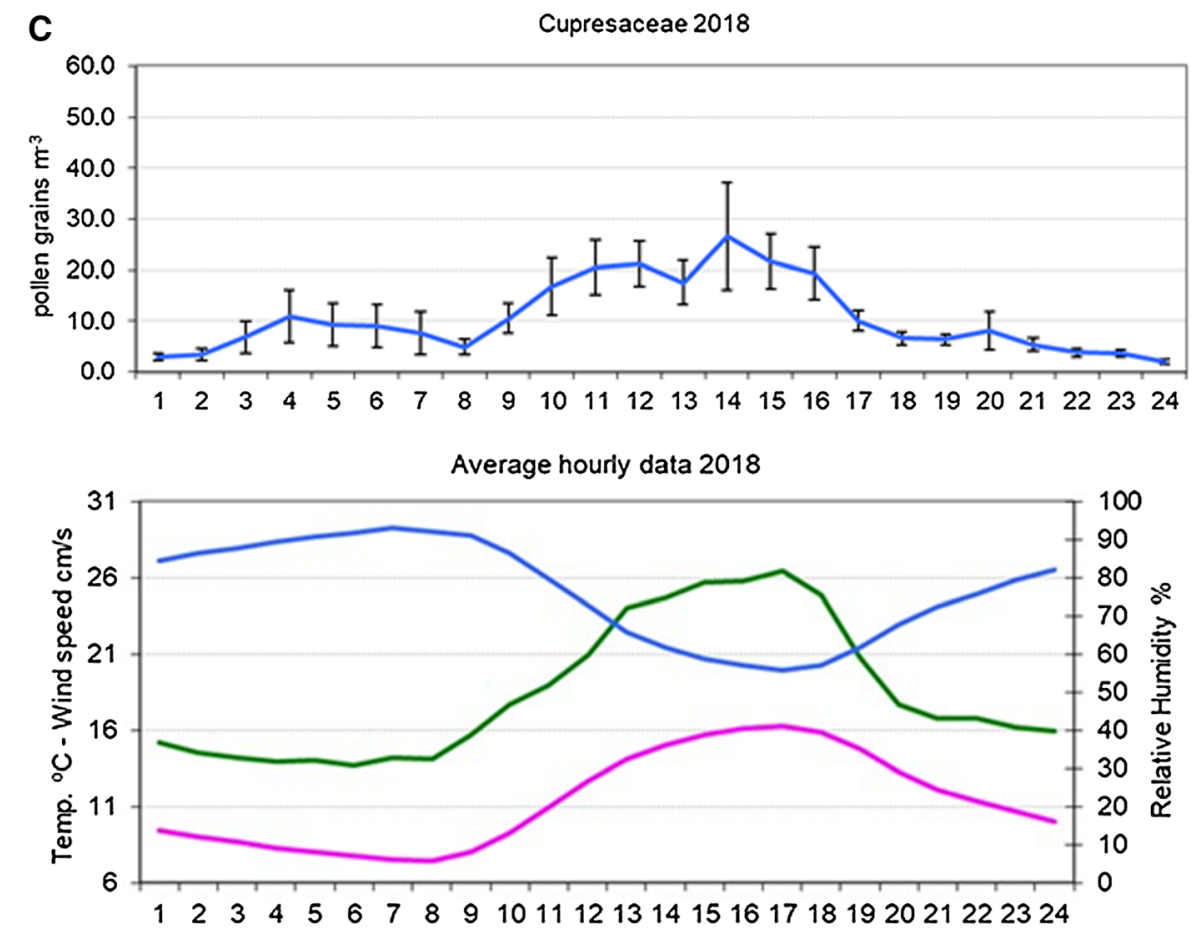

-AirTemp.Avg —WindSpd - Humidity.Avg

Fig. 6 continued 


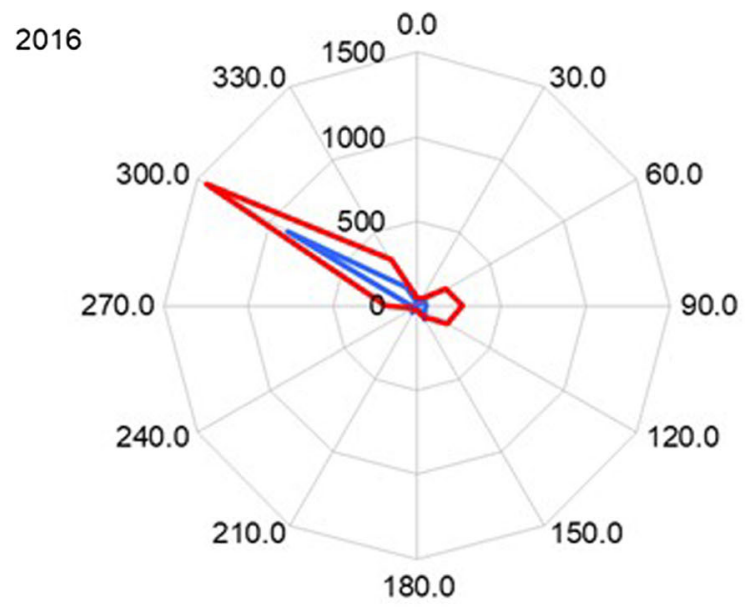

- Pollen hourly sums $(\times 0.05) \quad$ Wind frequencies
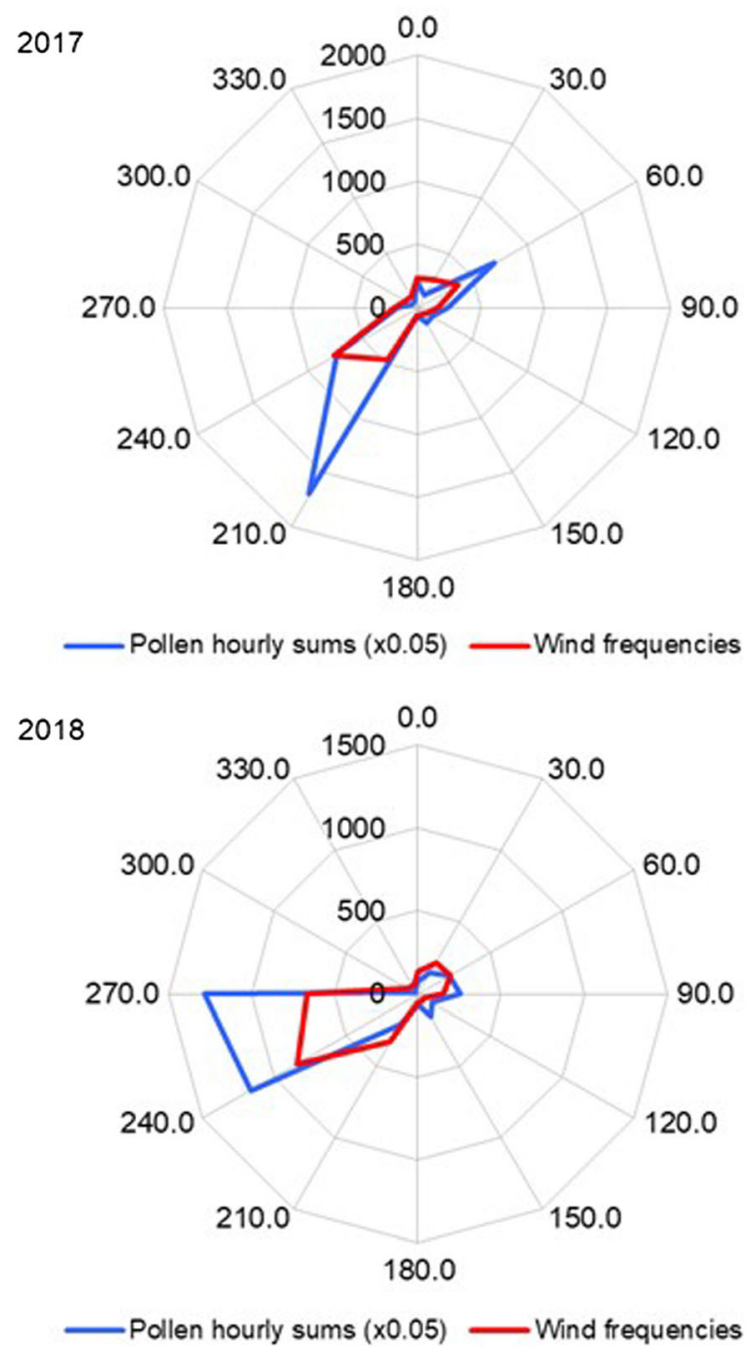

4Fig. 7 Wind direction from the period studied (January-April 2018) calculated from records every $10 \mathrm{~min}$

pollen, particularly when the weak winds prevail during a considerable part of the year. The highest concentrations appear when the winds are predominantly SW, which coincides with the greater presence of trees in that part of the city.

\section{Conclusions}

Cupressaceae airborne pollen was continuously present in the atmosphere of the sites studied, and the highest values were reached during end of November to mid-April. In all the studied years, the peaks of airborne pollen records did not match the phenology period for the different species and the precipitation did not allow a more precise correspondence. Within the meteorological parameters, the wind shows a great importance in relation to the source of origin of pollen grains, which seems to be a determining factor in the appearance of pollen grains of Cupressaceae in the air of the city of Badajoz. Our results could be explained because of the different phenological pollination patterns of Cupressaceae cultivated in the area studied. Furthermore, garden practices as growing more frequently $C$. sempervirens could explain the seasonal pattern found. The period of pollination of the Cupressaceae can be affected by the winter rains, although the highest counts occurred during the years of highest rainfall.

It is important to carry out phenological studies of the different species of this family, identifying clearly the peaks caused by the different species to recognize and prevent symptoms in allergic patients. In this way, this kind of urban studies may help to provide additional biological information about these urban species to predict the emission and dispersion of pollen. The establishment of a knowledge between pollen concentration, phenology and meteorology could be an important application in public health warnings. 
Table 5 Hourly values of Cupressaceae in 2016-2018

\begin{tabular}{|c|c|c|c|c|c|}
\hline & \multicolumn{4}{|l|}{ Hourly values } & \multirow{3}{*}{$\begin{array}{l}\text { Winds direction } \\
\text { predominant }\end{array}$} \\
\hline & \multicolumn{4}{|c|}{ Spearman's rank correlation coefficient $(\rho)$} & \\
\hline & Relative humidity & Wind speed & Temperature & Wind direction & \\
\hline \multicolumn{6}{|l|}{2016} \\
\hline Highest: 11:00-14:00 & -0.81 & 0.66 & $0.82 * *$ & -0.29 & WNW \\
\hline \multicolumn{6}{|l|}{ Lowest: 22:00-09:00 } \\
\hline \multicolumn{6}{|l|}{2017} \\
\hline Highest $10: 00-13: 00$ and $16: 00-18: 00$ & $0.68 * *$ & -0.74 & $0.59 * *$ & -0.64 & SW \\
\hline \multicolumn{6}{|l|}{ Lowest 20:00-08:00 } \\
\hline \multicolumn{6}{|l|}{2018} \\
\hline Highest: 10:00-16:00 & -0.73 & 0.89 & 0.73 & -0.79 & WSW \\
\hline Lowest: 21:00-02:00 & & & & & \\
\hline
\end{tabular}

Acknowledgements This work was possible by funds from research project PRIIB16029 and research group said GR18113 financed by the Regional Government, Junta de Extremadura (Spain). Particularly, the National Commission of Science and Technology of Mexico (CONACyT) funded A.M.C and Irish Environmental Protection Agency (EPA Program 2014-2020, Climate, 2017) funded J.M.M.M during part of the realization of this paper.

\section{References}

Aboulaich, N., Bouziane, H., El Kadiri, M., \& Riadi, H. (2008). Male phenology and pollen production of Cupressus sempervirens in Tetouan (Morocco). Grana, 47, 130-138.

AEMET. (2019). Climate statistics. Badajoz Airport (19812010). Agencia Estatal de Meteorología. Gobierno de España.

Aira, M., Dopazo, A., \& Jato, M. J. (2001). Aerobiological monitoring of Cupressaceae pollen in Santiago de Compostela (NW Iberian Peninsula) over six years. Aerobiologia, 17, 319-325.

Belmonte, J., Canela, M., Guardia, R., Guardia, R. A., Sbai, L., Vendrell, M., et al. (1999). Aerobiological dynamics of the Cupressaceae pollen in Spain, 1992-98. Polen, 10, 27-38.

Bikarma, S., Sultan, P., \& Singh, Bedi Y. (2018). Juniperus chinensis L. (Cupressaceae): A new taxa record for Himalaya and Extension of Geographic distribution in South Asia. National Academy Science Letters, 41(1), 69-73.

Bortenschlager, S. (1989). Aspects of pollen morphology in the Cupressaceae. Grana, 29(2), 129-138.

Bousquet, J., Cour, P., Guerin, B., \& Michael, F. B. (1984). Allergy in the Mediterranean area. I. Pollen counts and pollinosis of Montpellier. Clinical and Experimental Allergy, 14(3), 249-258.
Bousquet, J., Knani, J., Heijaoui, A., Fernando, R., Cour, P., Dhivert, H., et al. (1993). Heterogeneity of atop. I. Clinical and immunologic characteristics of patients allergic to cypress pollen. Allergy, 48(3), 183-188.

Burbach, G. J., Heinzerling, L. M., \& Hedenharther, G. (2009). GA2LEN skin test study II: Clinical relevance of inhalant allergen sensitizations in Europe. Allergy, 64, 1507-1515.

Burr, M. L. (1999). Grass pollen: Trends and predictions. Clinical \& Experimental Allergy, 29, 735-738.

Caballero, T., Romualdo, L., Crespo, J. F., Pascual, C., MuñozPereire, M., \& Martín-Esteban, M. (1996). Cupressaceae pollinosis in the Madrid area. Clinical and Experimental Allergy, 26, 197-201.

Cabrera, M., \& Subiza, J. (2008). Polinosis de invierno: la contaminación y el cambio climático agudizan y prolongan los síntomas. Alergia, 2, 1-8.

Caiaffa, M. F., Machia, L., Strada, S., Bariletto, G., Scarpelli, F., \& Tursi, A. (1993). Airborne Cupressaceae pollen in Southern Italy. Annals of Allergy, 71, 45-50.

Cariñanos, P., Galán, C., Alcázar, P., \& Domínguez, E. (2000). Meteorological phenomena affecting the presence of solid particles suspended in the air during winter. International Journal of Biometeorology, 44, 6-10.

Charpin, D., Calleja, M., Lahoz, C., Pi-chot, C., \& Waisel, Y. (2005). Allergy to cypress pollen. Allergy, 60, 293-301.

Charpin, D., Pichot, C., Belmonte, J., Sutra, J. P., Zidkova, J., Chanez, P., et al. (2017). Cypress pollinosis: From tree to clinic. Clinical Reviews in Allergy and Immunology, 2017, $1-22$.

Charpin, D., Pichot, C., Belmonte, J., Sutra, J. P., Zidkova, J., Chanez, P., et al. (2019). Cypress pollinosis: From tree to clinic. Clinical Reviews in Allergy and Immunology, 56(2), 174-195.

Chhaya, B., \& Johri, M. (1997). The gymnosperms. Berlin: Springer.

Christenhusz, M. J. M., Reveal, J. L., Farjon, A., Gardner, M. F., Mill, R. R., \& Chase, M. (2011). A new classification and 
linear sequence of extant gymnosperms. Phytotaxa, 19, 55-70.

D’Amato, G., Cecchi, L., Bonini, S., Nunes, C., Annesi-Maesano, I., Behrendt, H., et al. (2007). Allergenic pollen and pollen allergy in Europe. Allergy, 62(9), 976-990.

Damialis, A., Gioulekas, D., Lazopoulou, C., Balafoutis, C., \& Vokou, D. (2005). Transport of airborne pollen into the city of Thessaloniki: The effects of wind direction, speed and persistence. International Journal of Biometeorology, 49, 139-145.

Díaz de la Guardia, C., Alba, F., De Linares, C., Nieto-Lugilde, D., \& López-Caballero, J. (2006). Aerobiological and allergenic analysis of Cupressaceae pollen in Granada (Southern Spain). Journal of Investigational Allergology and Clinical Immunology, 16(1), 24-33.

Docampo, S., Recio, M., Trigo, M. M., Melgar, M., \& Cabezudo, B. (2007). Risk of pollen allergy in Nerja (Southern Spain): A pollen calendar. Aerobiologia, 23, 189-199.

Emberlin, J., Mullins, J., Corden, J., Jones, S., Millington, W., Brooke, M., et al. (1999). Regional variations in grass pollen seasons in the UK, long-term trends and forecast models. Clinical and Experimental Allergy, 29(3), 347-356.

Fernández-Rodríguez, S., Tormo-Molina, R., Maya-Manzano, J. M., Silva-Palacios, I., \& Gonzalo-Garijo, Á. (2014). Comparative study of the effect of distance on the daily and hourly pollen counts in a city in the south-western Iberian Peninsula. Aerobiologia, 30, 173-187.

Frenguelli, G., Bricchi, E., Romano, B., Mincigrucci, G., \& Spicksma, F. (1989). A predictive study of the beginning of the pollen season for Gramineae and Olea europaea L. Aerobiologia, 5, 64-70.

Galán C., Cariñanos P., Alcázar P., \& Dominguez-Vilches, E. (2007). Spanish aerobiology network (REA) management and quality manual. Servicio de Publicaciones Universidad de Córdoba. ISBN 978-84-690-6353-8.

Galán, C., Cuevas, J., Infante, F., \& Domínguez-Vilches, E. (1989). Seasonal and diurnal variation of pollen from Gramineae in the atmosphere of Córdoba (Spain). Allergologic et Immunopathology, 17(5), 245-249.

Galán, C., Fuillerat, M. J., Comtois, P., \& Domínguez-Vilches, E. (1998). Predictive study of Cupressaceae pollen season onset, severity, máximum value and maximum value date. Aerobiologia, 14, 1995-1999.

García-Mozo, H., Chuine, I., Aira, M. J., Belmonte, J., Bermejo, D., Díaz de la Guardia, C., et al. (2008). Regional phenological models for forecasting the start and the end of the Quercus pollen season in Spain. Agricultural and Forest Meteorology, 148, 372-380.

Guerra, F., Daza, J. C., Miguel, R., Moreno, C., Galán, C., Domínguez, E., et al. (1996). Sensitivity to Cupressus: Allergenic significance in Córdoba (Spain). Journal of Investigational Allergology and Clinical Immunology, 6(2), 117-120.

Hall, S. (1992). Comparative pollen influx at a nine-array in the grand prairie of Northern Texas. The Texas Journal of Science, 44, 469-474.

Hidalgo, P., Galán, G., \& Domínguez, E. (2003). Male phenology of the three species of Cupressus: Correlation with airborne pollen. Trees, 17(4), 336-344.
Hirst, J. M. (1952). An automatic volumetric spore trap. Annals of Applied Biology, 39(2), 257-265.

Hrabina, M., Dumur, J. P., Sicard, H., Viatte, A., \& Andre, C. (2003). Diagnosis of cypress pollen allergy: In vivo and in vitro standardization of a Juniperus ashei pollen extract. Allergy, 58(8), 808-813.

James, W. B. (2015). The gymnosperms handbook. A practical guide to extant families and genera of the world. Hertford: Plant Gateway.

Katz, D., Dzul, A., Kendel, A., \& Batterman, S. (2019). Effect of intra-urban temperature variation on tree flowering phenology, airborne pollen, and measurement error in epidemiological studies of allergenic pollen. Science of the Total Environment, 653, 1213-1222.

Keynan, N., Waisel, Y., Shomerilan, A., Goren, A., \& Brener, S. (1991). Annual variations of airborne pollen in the coastal plain of Israel. Grana, 30, 477-480.

Lahoz, C., Cortageno, I., Civantos, E., López, E., Cárdaba, B., Llanes, E., et al. (2003). Alergenos de las Cupresáceas. Allergology and Clinical Immunology, 18(3), 35-39.

Maya-Manzano, J. M., Sadyś, M., Tormo Molina, R., Fernández Rodríguez, S., Gonzalo Garijo, A., Oteros Moreno, J. A., et al. (2017b). Relationship between airborne pollen grains, wind direction and land cover using GIS and circular statistics. Science of the Total Environment, 584-585, 603-613.

Maya-Manzano, J. M., Tormo Molina, R., Fernández Rodríguez, S., Silva Palacios, I., \& Gonzalo Garijo, A. (2017c). Distribution of ornamental urban trees and their influence on airborne pollen in the SW of Iberian Peninsula. Landscape and Urban Planning, 157, 434-446.

Meier, U. (1997). BBCH-monograph: Growth stages of plants (p. 622). Berlin: Blackwell Wissenschafts-Verlag. ISBN 3-8263-3152-4.

Meier, U. (2001). Growth stages of mono-and dicotyledonous plants. BBCH monograph (2nd Ed.). Federal Biological Research Centre for Agriculture and Forestry. http://pub. jki.bund.de/index.php/BBCH/article/view/461.

Miyao, M., Furuta, M., Ozawa, K., Kondo, T., Sakakibara, H., Ishihara, S., et al. (1993). Morbidity of allergenic rhinitis based on the National Health Insurance records of Japan. The Tohoku Journal of Experimental Medicine, 169(4), 345-350.

Monroy-Colín, A., Silva-Palacios, I., Tormo-Molina, R., MayaManzano, J. M., \& Fernández-Rodríguez, S. (2018). Environmental analysis of airborne pollen occurrence, pollen source distribution and phenology of Fraxinus angustifolia. Aerobiologia, 34(4), 269-283.

Moral de Gregorio, A. (2003). Aerobiología y polinosis por Cupresáceas en España. Alergología e Inmunología Clinica, 18(Extraordinario 3), 24-39.

Nilsson, S., \& Persson, S. (1981). Tree pollen spectra in the Stockholm region (Sweden), 1973-1980. Grana, 20(3), 179-182.

Norris-Hill, J., \& Emberlin, J. (1991). Diurnal variation of pollen concentration in the air of north-central London. Grana, 30, 229-234.

NSI. (2018). Population by cities. Madrid: National Institute of Statistics.

Okuyama, Y., Matsumoto, K., Okochi, H., \& Igawa, M. (2007). Adsorption of air pollutants on the grain surface of 
Japanese cedar pollen. Atmospheric Environment, 41(2), 253-260.

Pace, L., Boccacci, L., Casilli, M., Di Carlo, P., \& Fattorini, S. (2017). Correlations between weather conditions and airborne pollen concentration and diversity in a Mediterranean high-altitude site disclose unexpected temporal patterns. Aerobiologia, 34, 75-87.

Page, C. N. (1990). Cupressaceae. In K. U. Kramer \& P. $\mathrm{S}$. Green (Eds.), Pteridophytes and gymnosperms. The families and genera of vascular plants (Vol. 1). Berlin: Springer.

Pahus, L., Gouitaa, M., Sofalvi, T., Alagha, K., Gras, D., Chanez, P., et al. (2018). Cypress pollen allergy is responsible for two distinct phenotypes of allergic rhinitis different from other pollinosis. European Annals of Allergy and Clinical Immunology, 50(1), 28-35.

Pérez-Badia, R., Vaquero, C., Sardinero, S., Galán, C., \& García-Mozo, H. (2010). Intradiurnal variations of allergenic tree pollen in the atmosphere of Toledo (Central Spain). Annals of Agricultural Environmental Medicine, 17, $37-43$.

Recio, M., Cabezudo, B., Trigo, M. M., \& Toro, J. F. (1998). Pollen calendar of Malaga (Southern Span), 1991-1995. Aerobiologia, 14(2), 101-107.

Rodríguez-Rajo, F., Jato, V., \& Aira, M. (2003). Pollen content in the atmosphere of Lugo (NW Spain) with reference to meteorological factors (1999-2001). Aerobiologia, 19, 213-225.

Schulzz, C., Knopf, P., \& Stützel, T. H. (2005). Identification key to the Cypress family (Cupressaceae). Feddes Repertorium, 116, 96-146.

Silva-Palacios, I., Fernández-Rodríguez, S., Durán-Barroso, P., Tormo-Molina, R., Maya-Manzano, J. M., \& GonzaloGarijo, Á. (2016). Temporal modelling and forecasting of the airborne pollen of Cupressaceae on the southwestern Iberian Peninsula. International Journal of Biometeorology, 60(2), 297-306.

Solomon, W., \& Mathews, K. (1978). Aerobiology and inhalant allergens. In E. Middleton, C. Reed, \& E. Ellis (Eds.), Allergy principles and practice (Vol. 2). St. Louis: Mosby.

Staffolani, L., Velasco-Jiménez, M. J., Galán, C., \& Hruska, K. (2011). Allergenicity of the ornamental urban flora: Ecological and aerobiological analyses in Córdoba (Spain) and Ascoli Piceno (Italy). Aerobiologia, 27(3), 229-246.

Suarez-Cervera, M., Castells, T., Vega-Maray, A., Civantos, E., del Pozo, V., Fernandez-Gonzalez, D., et al. (2008). Effects of air pollution on cup a 3 allergen in Cupressus arizonica pollen grains. Annals of Allergy, Asthma \& Immunology, 101(1), 57-66.

Subiza, J., Brito, F., \& Pola, J. (1998). Pólenes alergénicos y polinosis en 12 ciudades españolas. Revista Española de Alergología e Inmunología Clínica, 13, 45-58.

Tedeschini, E., Rodríguez-Rajo, F. J., Caramiello, R., Jato, V., \& Franguelli, G. (2006). The influence of climate changes in Platanus spp. Pollination in Spain and Italy. Grana, 2006(45), 222-229.

Tormo-Molina, R., Maya-Mannzano, J. M., Fernández-Rodriguez, S., Gonzalo, Á., \& Silva, I. (2013). Influence of environmental factors on measurements with Hirst pollen traps. Grana, 52, 59-70.

Tormo-Molina, R., Maya-Manzano, J. M., Silva-Palacios, I., Fernández-Rodríguez, S., \& Gonzalo-Garijo, A. (2015). Flower production and phenology in Dactylis glomerata. Aerobiologia, 31(4), 469-479.

Tormo-Molina, R., Silva, I., Gonzalo, A., Moreno, A., Pérez, R., \& Fernández, S. (2011). Phenological records as a complement to aerobiological data. International Journal of Biometeorology, 55, 51-65.

Tormo-Molina, R., Silva, I., Muñoz, A., Tavira, J., \& Moreno, A. (2001). Environmental factors affecting airborne pollen concentration in anemophilous species of Plantago. Annals of Botany, 87, 1-8.

Torrigiani, T., Cecchi, L., Morabito, M., Onorari, M., Domeneghetti, M. P., \& Orlandini, S. (2006). Influence of meteorological conditions on male flower phenology of Cupressus sempervirens and correlation with pollen production in Florence. Trees, 21, 507-514.

Torrigiani, T., Moriondo, M., Bindi, M., Cecchi, L., \& Orlandini, S. (2007). A phenological model to evaluate the impact of the expected climate change on Cupressaceae main pollen season in Central Italy. Italian Journal of Agrometeorology, Speciale Fenologia, (3), 45-51.

Tortajada, B., \& Mateu, I. (2008). Cupressaceae pollen in the atmosphere of Valencia (East of Spain) and relationships with meteorological parameters. Polen, 18, 51-59.

Velasco-Jiménez, M. J., Alcázar, P., Valle, A., Trigo, M. M., Minero, F., Dominguez-Vilches, E., et al. (2013). Aerobiological and ecological study of the potentially allergenic ornamental plants in south Spain. Aerobiologia, 30(1), 91-101.

Wang, Q., Morita, J. N. S., Wu, D., Gong, X., Suzuki, M., Miwa, M., et al. (2010). Field investigation on modification of Japanese cedar pollen allergen in urban air-polluted area. World Academy of Science, Engineering and Technology, 69, 624-629.

Water, P., \& Levetin, E. (2001). The contribution of upwind pollen sources to the characterization of Juniperus ashei phenology. Grana, 40, 133-141.

Watson, F., \& Eckenwalder, J. E. (1993). Cupressaceae. In Flora of North America Editorial Committee (Eds.), Flora of North America North of Mexico, Vol. 2. Oxford: Oxford University Press.

Zerboni, R., Arrigioni, P. V., Manfredi, M., Rizzotto, M., Paoletti, L., \& Ricceri, C. (1991). Geobotanical and phenological monitoring of allergenic pollen grains in the Florence area. Grana, 30, 357-363. 